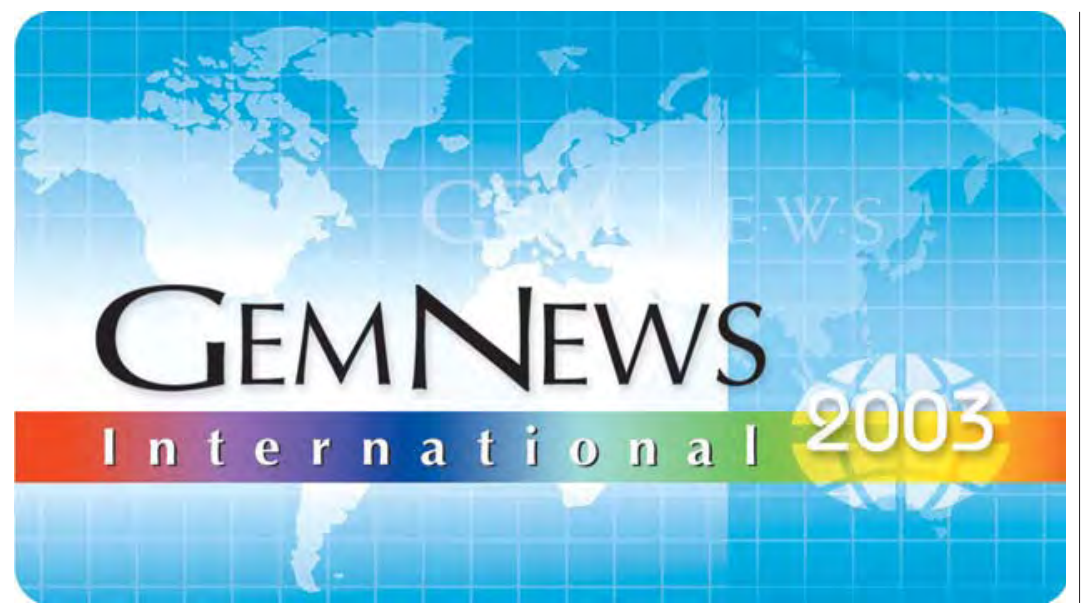

\title{
GDITOR
}

Brendan M. Laurs (blaurs@gia.edu)

\section{CONTRIBUTING EDITORS}

Emmanuel Fritsch, IMN, University of

Nantes, France (fritsch@cnrs-imn.fr)

Henry A. Hänni, SSEF, Basel, Switzerland

(gemlab@ssef.ch)

Kenneth V. G. Scarratt, AGTA Gemological Testing

Center, New York (kscarratt@email.msn.com)

Karl Schmetzer, Petershausen, Germany

(schmetzerkarl@hotmail.com)

James E. Shigley, GIA Research,

Carlsbad, California (jshigley@gia.edu)

Christopher P. Smith, GIA Gem Laboratory,

New York (chris.smith@gia.edu)

\section{DIAMONDS}

A comparison of three historic blue diamonds. This summer's "Splendor of Diamonds" exhibition at the Smithsonian Institution in Washington, D.C., presented a unique opportunity for the public to view seven of the world's rarest diamonds (see, e.g., J. M. King and J. E. Shigley, "An important exhibition of seven rare gem diamonds," Summer 2003 Gems « Gemology, pp. 136-143). The closing of the exhibition brought another opportunity-for the contributors of this entry to compare the properties of three of the largest documented strongly colored blue diamonds. Two of these diamonds, the $45.52 \mathrm{ct}$ Hope and the 30.62 ct Blue Heart, are part of the Smithsonian's permanent collection; the third, the 27.64 ct Heart of Eternity, was part of the special exhibit (figure 1). Arrangements were made to remove the Hope and the Blue Heart from their mountings and to allow the contributors one evening to examine and test them in conjunction with the Heart of Eternity prior to its being returned to its owner.

GIA has graded all three diamonds since the 1995 introduction of enhancements to its colored diamond color grading system (see J. M. King et al., "Color grading of colored diamonds in the GIA Gem Trade Laboratory," Winter 1994 Gems ↔ Gemology, pp. 220-242). The Hope diamond was described as Fancy Deep grayish blue in an updated grading performed in 1996; the Blue Heart was graded Fancy Deep blue in 1997, and the Heart of Eternity was graded Fancy Vivid blue in 1999. Given the different color descriptions for each of these diamonds, this was a special chance to see how the color appearances related to the terms defined by the grading system.

In GIA's system, fancy-grade terminology is used to describe a range of the combined effect of tone (the lightness to darkness of a color) and saturation (the strength or purity of a color). For blue diamonds, for example, Fancy Deep describes those of medium to dark tone and moderate to strong saturation. Fancy Vivid describes those that are medium to dark in tone and strong to very strong in saturation. These fancy-grade ranges are further divided by color terms such as blue, blue-gray, or bluish gray to refine the location of the color appearance. "Cooler" colors, such as blue, appear more grayish or gray as they become darker in tone and/or weaker in saturation, and modifiers of grayish or gray are used in the color description to reflect this aspect. When the color space for blue diamonds was discussed by J. M. King et al. ("Characterizing natural-color type IIb blue diamonds," Winter 1998 Gems ↔ Gemology, pp. 246-268), the authors noted that the range of saturation in which blue diamonds occur is relatively compressed. This means the appearance differences between color terms can be more subtle than similar terms for other colors.

From the report descriptions, one would expect these three diamonds to have similar tone (with small variations) and subtle differences in saturation. The Hope, which has been described as "steely" in appearance, is less saturated than the other two. The Heart of Eternity has the strongest color, with the Blue Heart falling between them. The Heart of Eternity's color is strong

Editor's note: Interested contributors should send information and illustrations to Brendan Laurs at blaurs@gia.edu (e-mail), 760-603-4595 (fax), or GIA, 5345 Armada Drive, Carlsbad, CA 92008. Original photos will be returned after consideration or publication.

GEMS \& GeMOlOGY, Vol. 39, No. 4, pp. 322-346

(C) 2003 Gemological Institute of America 


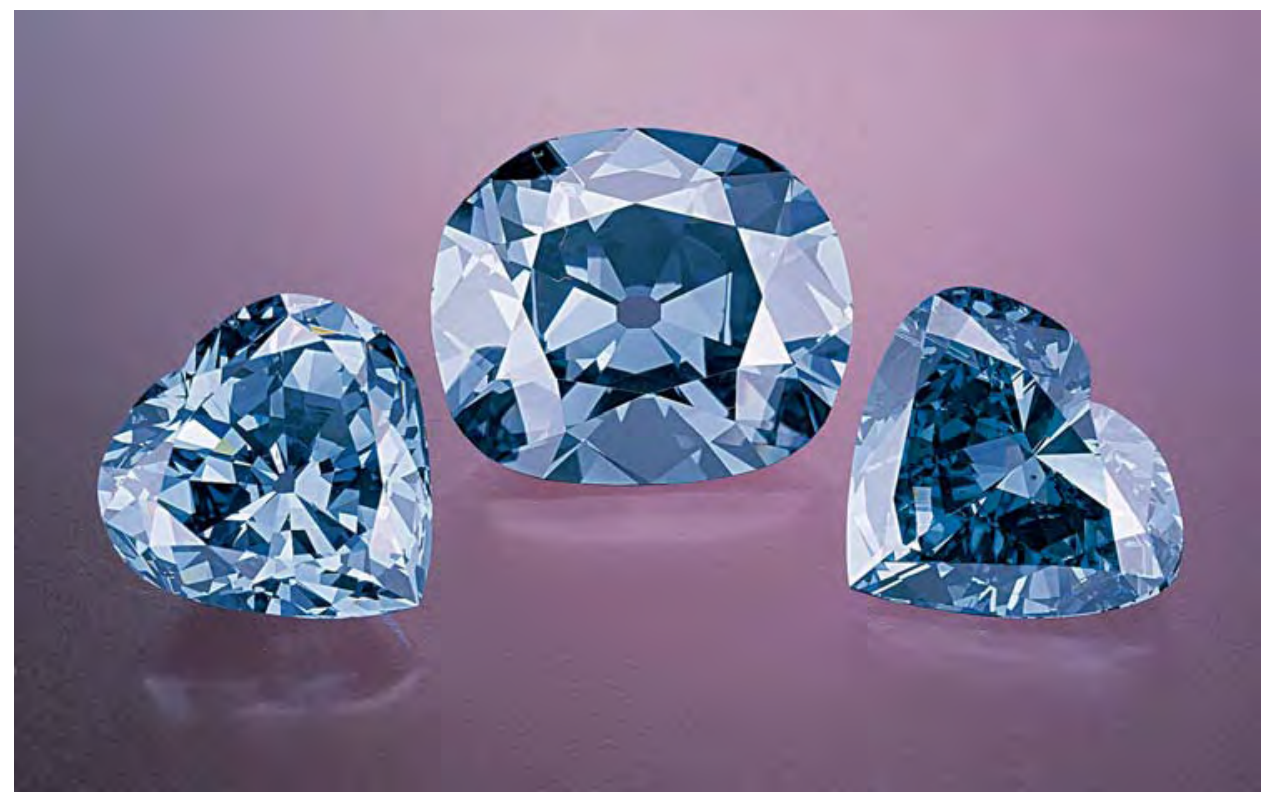

Figure 1. Shown here from left to right, the $30.62 \mathrm{ct}$ Blue Heart, the $45.52 \mathrm{ct}$ Hope, and the $27.64 \mathrm{ct}$ Heart of Eternity are three of the largest strongly colored blue diamonds that have been documented gemologically. To encounter one such diamond is extremely rare, and to have an opportunity to observe all three together was a unique experience. Photo by Shane McClure.

enough for it to merit a different grade range (i.e., Fancy Vivid). Figure 2 shows the relationship of these three diamonds on a section of a tone/saturation grid.

This occasion also presented a chance to view the unique phosphorescence associated with some naturalcolor type IIb blue diamonds. Type IIb blue diamonds that phosphoresce do so almost solely in response to short-wave UV radiation and do not react to long-wave. King et al. (1998) noted that three-quarters of the blue diamonds that phosphoresced showed a very weak to weak reaction. The most common color was a chalky blue to green, with rare red or orangy red reactions. The
Hope diamond's strong red phosphorescence to shortwave UV radiation has been described a number of times land is illustrated in R. Crowningshield, "Grading the Hope diamond," Gems \&) Gemology, Summer 1989, p. 93), so it was interesting to note a similar reaction in the Heart of Eternity. When the UV source was turned off, both diamonds showed a similar intensity of phosphorescence; however, while the Hope's could be observed for more than a minute, the Heart of Eternity's faded rather quickly. In addition, the Hope's reaction was a slightly warmer red than that of the Heart of Eternity. The Blue Heart exhibited a more typical, very subtle white to

Figure 2. The three blue diamonds described here are placed on a portion of a tone/saturation grid to illustrate their relationship in color space. All are relatively similar in tone (lightness to darkness) but differ in saturation (the strength or purity of the color). The Hope is the least saturated, the Heart of Eternity is the most saturated, and the Blue Heart is between them in saturation and slightly lighter in tone.

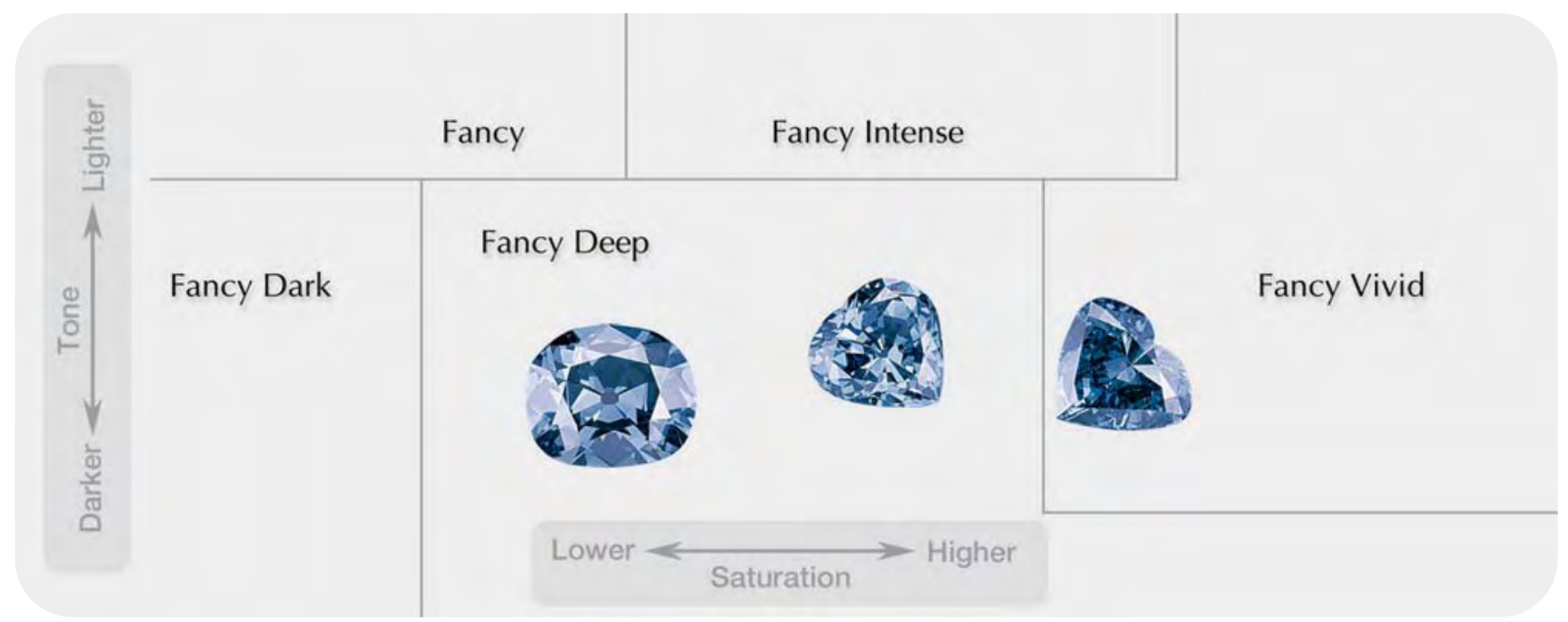




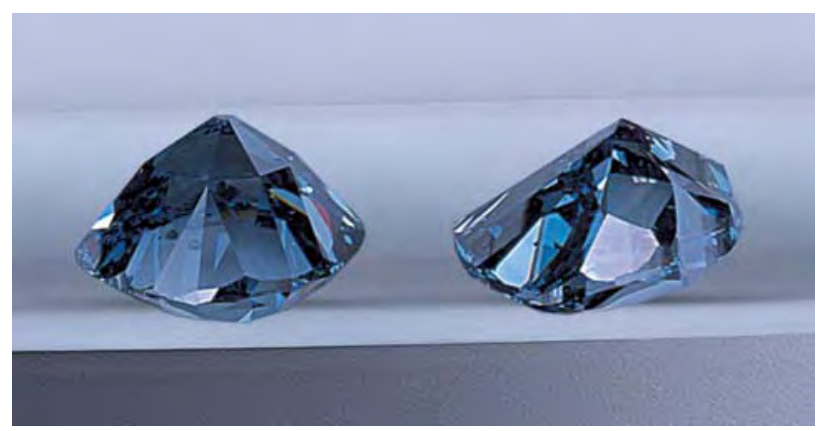

Figure 3. While the cutting of each diamond is approached individually, a general difference in cutting philosophy is seen here in the profile view of the two heart-shaped diamonds. The Blue Heart (left) was cut in the early part of the 20th century and the Heart of Eternity (right) was cut in the 1990s. The two faceting approaches result in different face-up appearances. Photo by Shane McClure.

chalky blue reaction that also faded quickly. There is no known explanation for why two of these diamonds show such a dramatic reaction and the third does not.

The differences in cutting philosophy between the two heart-shaped diamonds also were intriguing (figure 3). Smithsonian records indicate that the Blue Heart was cut in the early part of the 20th century; we know that the Heart of Eternity was cut in the 1990s. Bearing in mind that each piece of rough is approached individually to achieve the best weight retention, color, clarity, and cut, there are still distinct differences in style between the two. The culet on the Blue Heart is near the center of the diamond, and is surrounded by radiating facets similar to how sapphires are cut. The edges between facets are sharp and well-defined, which often results in more brilliance in the face-up position (see again figure 1). The Heart of Eternity has a French culet (four pavilion mains) and a number of relatively large flat facets on the pavilion near the girdle. The angle between adjacent facets is rather shallow in a number of areas on the pavilion, making these facets appear less distinct. These cutting aspects help deepen and intensify the face-up color appearance of the Heart of Eternity.

These contributors also performed infrared spectroscopy on all three diamonds. The Hope has a large culet facet, and the infrared beam entered through the table and passed out the culet, for a path length of $12 \mathrm{~mm}$ through the diamond (assuming no internal reflections). The Blue Heart has a small culet that is subparallel to the table (11.9 $\mathrm{mm}$ in this dimension); thus, the infrared beam was aimed directly through these two facets. The Heart of Eternity does not have a culet facet, so the spectrum was taken across the width of the heart, with a beam path length of approximately $20 \mathrm{~mm}$ (again, assuming no internal reflections).

Mid-infrared spectra $\left(8000-400 \mathrm{~cm}^{-1}\right)$ were obtained with a Bio-Rad Excalibur Fourier-transform infrared spectrometer using a KBr beam splitter and DTGS detector at $4 \mathrm{~cm}^{-1}$ resolution. The infrared spectrum of the Hope diamond is shown in figure 4 . The absorption characteristics of the Blue Heart and the Heart of Eternity were essentially identical to that of the Hope diamond, but due to lower transmission of light through these samples the spectra were of lower quality.

There are two principal causes for the absorption features in this energy range: lattice vibrations of the diamond and electronic transitions due to substitution

Figure 4. The infrared spectrum of the Hope diamond shows features that are consistent with boron-

induced blue color and type IIb diamonds in gen-

eral (see text). Note that portions of some bands in the $3800-1600 \mathrm{~cm}^{-1}$ region were actually off the scale of the spectrometer.

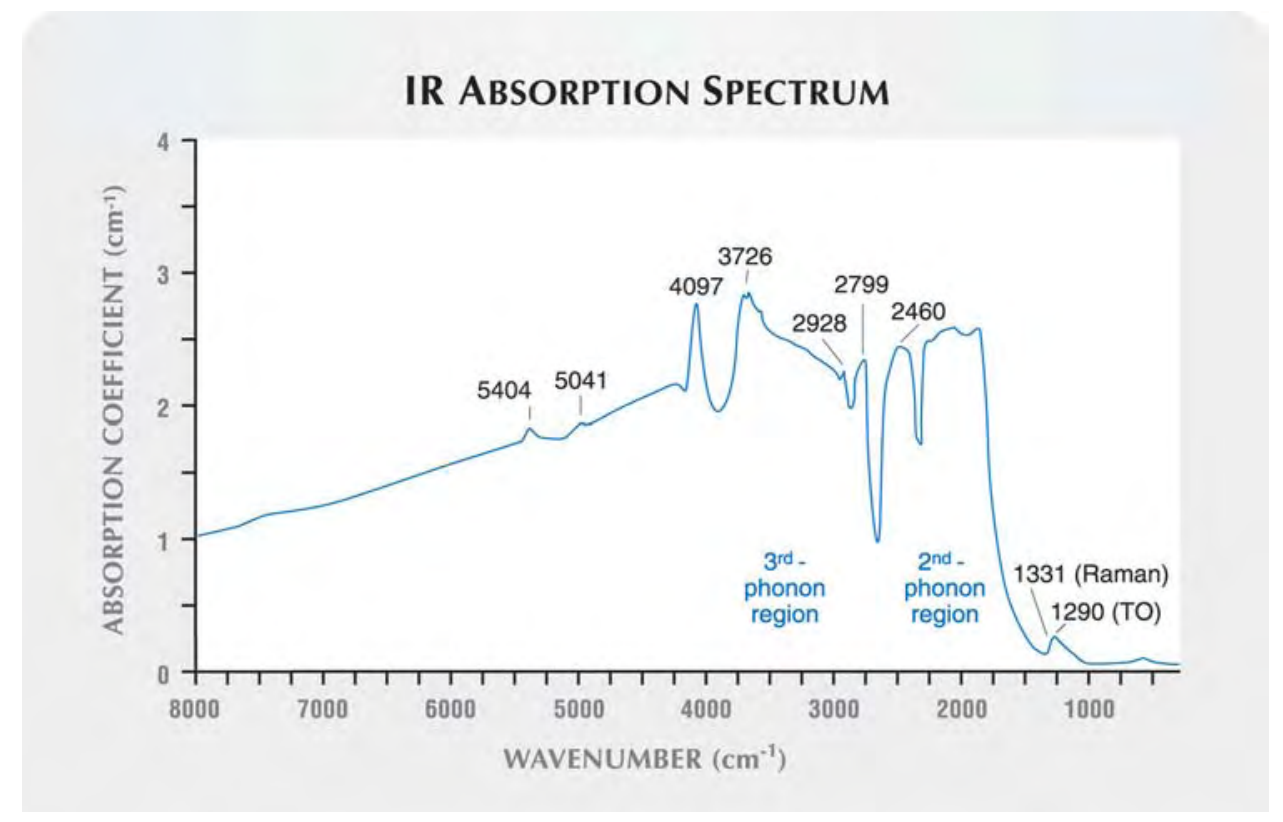


of boron into the diamond structure. The lattice vibrations appear from 4000 to $1200 \mathrm{~cm}^{-1}$, and consist of the transverse optic (TO) mode, the Raman-active mode, and bands in the second- and third-phonon regions (King et al., 1998). The broad absorbance that results from substitution of small amounts of boron for carbon in the diamond structure starts roughly at $3000 \mathrm{~cm}^{-1}$ and extends into the near-infrared and red region in the visible spectrum; it is the cause of the blue color (see S.D. Smith and W. Taylor, "Optical phonon effects in the infra-red spectrum of acceptor centres in semiconducting diamond," Proceedings of the Physical Society, London, Vol. 79, 1962, pp. 1142-1153; I. G. Austin and R. Wolfe, "Electrical and optical properties of a semiconducting diamond," Proceedings of the Physical Society, Vol. 69B, No. 3, 2003, pp. 329-338). As reported by Smith and Taylor (1962), the other absorption features seen in figure 4 are due to boron-related electronic transitions $\left(2928,2799\right.$, and $\left.2460 \mathrm{~cm}^{-1}\right)$ and the combination modes of the boron transitions and lattice vibrations $\left(5404,5041,4097\right.$, and $\left.3726 \mathrm{~cm}^{-1}\right)$. The spectra of all three blue diamonds lacked any detectable nitrogen bands in the $1400-1000 \mathrm{~cm}^{-1}$ region, consistent with the definition of type II diamonds.

To our knowledge, this is the first mid-infrared spectrum obtained on the Hope diamond; it shows features consistent with the presence of boron as the cause of the blue coloration and its categorization as a type IIb diamond.

John M. King (jking@gia.edu) GIA Gem Laboratory, New York

Elizabeth A. Johnson and Jeffrey E. Post Smithsonian Institution, Washington, D.C.

A natural yellow diamond with nickel-related optical centers. A Fancy Light yellow 2.95 ct round brilliant diamond was recently submitted to the SSEF Swiss Gemmological Institute for color authenticity determination (figure 5). In the course of standard testing, we noticed the presence in its UV-visible spectrum of clear nickel-related optical centers, which are usually encountered in flux-grown synthetic diamond. Further spectroscopic analysis, as described below, in combination with the growth patterns, proved that this Ni-containing diamond was natural and not a synthetic. Although the presence of nickel in natural diamonds has been previously documented (C. J. Noble et al., "Electron paramagnetic resonance investigations of nickel defects in natural diamonds," Journal of Physics: Condensed Matter, Vol. 10, 1998, pp. 11781-11793), we are not aware of any previous mention of this in the gemological literature.

Microscopic observation of this diamond revealed several small black-to-brown inclusions of unknown origin. Numerous swirl-like patterns were visible with darkfield illumination, and were more distinct when crossed polarizers were used. With long-wave UV radiation, the stone showed a strong "lemon" yellow reaction, which was mostly even except for a few weaker zones close to the culet. The short-wave UV reaction was similar in color though weaker in intensity. No magnetic test was performed.

The infrared spectrum showed a strong platelet-related peak (higher than the two-phonon zone) and a large and saturated absorption band between 1300 and 1050 $\mathrm{cm}^{-1}$. These features are typical for type Ia diamonds that contain significant concentrations of nitrogen. Several characteristic peaks in both the one- and three-phonon zones indicated that the diamond also contained a moderate concentration of hydrogen. This is consistent with its yellow UV fluorescence. If we consider both the presence of a well-defined $1010 \mathrm{~cm}^{-1}$ peak and the absence of the $484 \mathrm{~cm}^{-1}$ peak, it is reasonable to assume that the majority of nitrogen was present as B aggregates.

The UV-Vis absorption spectrum, recorded at approximately $-120^{\circ} \mathrm{C}$, showed a strong $\mathrm{N} 3$ center, with an absorption coefficient of $2.0 \mathrm{~cm}^{-1}$ at $415.2 \mathrm{~nm}$. A series of weak peaks (343.6, 347.3, 360.3, 363.5, and $366.9 \mathrm{~nm}$ ) were recorded that so far have been described only in synthetic diamonds (J. E. Field, The Properties of Natural and Synthetic Diamond, Academic Press, London, 1992). Also present was another series of weak peaks $(467.9,473.0$, 477.5 , and $546.7 \mathrm{~nm}$ ) that have been previously attributed to nickel- and nitrogen-related absorptions in annealed type Ib synthetic diamonds (J. E. Shigley et al., "The gemological properties of Russian gem-quality synthetic yellow diamonds," Winter 1993 Gems ↔ Gemology, pp. 228-248). In addition, a weak peak was recorded at 793.3

Figure 5. This $2.95 \mathrm{ct}$ Fancy Light yellow natural diamond was found to contain Ni-related absorption features in the UV-visible region that have previously been associated only with synthetic diamonds. Photo by M. Krzemnicki, @ SSEF.

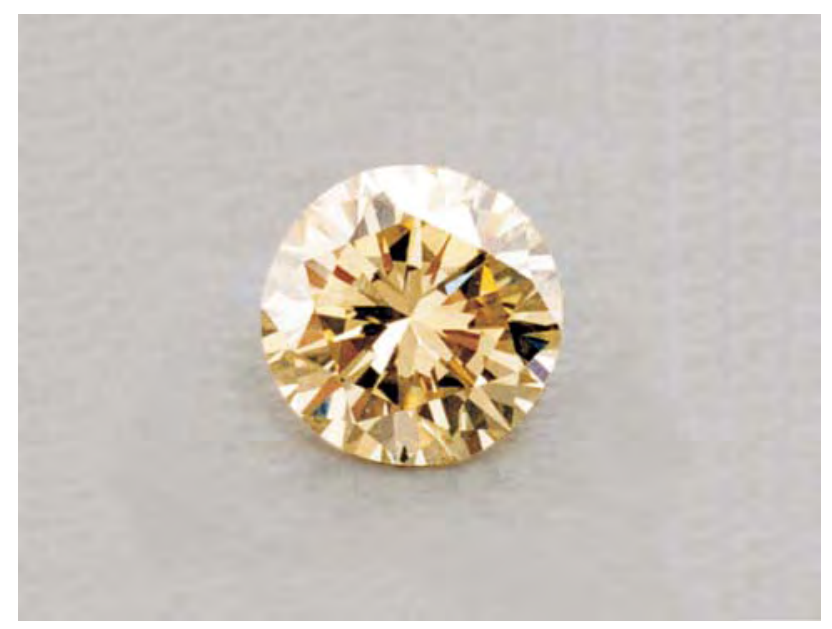




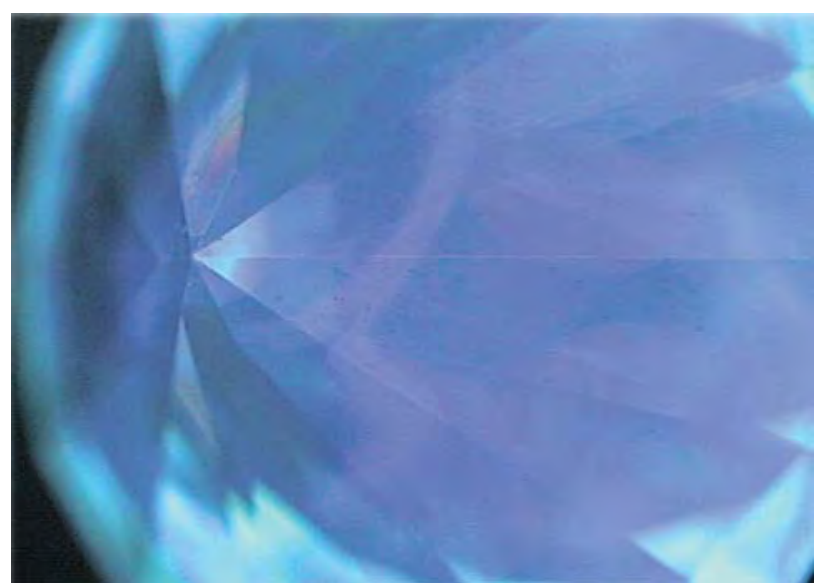

Figure 6. This De Beers DiamondView image of the Fancy Light yellow diamond with Ni-N-related optical centers shows irregular patterns of blue fluorescence, indicative of natural origin. Photo by J.-P. Chalain, (C) SSEF.

$\mathrm{nm}$ (with an absorption coefficient of $0.1 \mathrm{~cm}^{-1}$ ), which is commonly observed in both natural and synthetic nickelcontaining diamonds and is almost certainly due to a nickel-nitrogen complex (D. Fisher, pers. comm., 2003).

The Raman photoluminescence spectrum of this diamond, recorded at approximately $-120^{\circ} \mathrm{C}$ with a $514.5 \mathrm{~nm}$ (green) laser, showed two peaks of moderate intensity at 640.5 and $693.9 \mathrm{~nm}$, and a very strong peak at $700.5 \mathrm{~nm}$. This last peak is usually seen in natural type Ia diamonds. None of the Raman photoluminescence peaks could be ascribed to Ni-related optical centers.

Notwithstanding the features seen in the UV-Vis spectrum, the natural origin of this diamond was supported by many properties, the first of which was the presence of irregular growth patterns. A DiamondView image (figure 6) revealed blue fluorescence with irregular patterns close to the culet and no phosphorescence (a synthetic diamond would have displayed regular cubo-octahedral growth patterns, as shown in C. M. Welbourn et al., "De Beers natural versus synthetic diamond verification instruments," Fall 1996 Gems ↔) Gemology, pp. 156-169). The high concentration of nitrogen, especially in the form of B aggregates, the presence of a high platelet peak, and a strong N3 center are also valuable indications for natural diamond.

In conclusion, examination of this interesting diamond allowed us to observe, for the first time, Ni-related defects in a natural diamond by means of UV-visible absorption spectroscopy. The natural origin of the diamond's color was proven by the absence of any coating, as well as the lack of any spectroscopic features indicative of HPHT treatment or irradiation and annealing.

This contributor is grateful to Dr. D. Fisher for providing constructive comments.

J.-P. Chalain (gemlab@ssef.ch) SSEF Swiss Gemmological Institute, Basel

\section{COLORED STONES AND ORGANIC MATERIALS}

Gem-quality afghanite. While on a gem-buying expedition in Peshawar, Pakistan, Dudley Blauwet, a gem dealer from Louisville, Colorado, obtained five cabochons and an excellent crystal specimen of afghanite. The stones were said to have come from Kiran, Kokcha Valley, Badakhshan Province, Afghanistan. Although in the past these contributors have seen a few afghanite crystals at various gem and mineral shows, we had never seen gems fashioned from this rare mineral, so for us this was a first opportunity to examine polished samples of afghanite. A member of the cancrinite group, the chemical formula of afghanite is $(\mathrm{Na}, \mathrm{Ca}, \mathrm{K})_{8}(\mathrm{Si}, \mathrm{Al})_{12} \mathrm{O}_{24}\left(\mathrm{SO}_{4}, \mathrm{Cl}_{1} \mathrm{CO}_{3}\right) \cdot \mathrm{H}_{2} \mathrm{O}$. It has a hardness of $5^{11 / 42-6}$ on the Mohs scale.

The crystal measured $23.0 \leftrightarrow 14.5 \mathrm{~mm}$ and was partially embedded in white calcite matrix (figure 7). Although we could not find it reported in the literature, an interesting feature of afghanite that should prove useful in its identification is its strong, bright orange fluorescence to longwave UV radiation (see, e.g., figure 8), which we also observed in all five cabochons. All of the samples were inert to short-wave UV radiation, and no phosphorescence was observed in either case.

The five cabochons (ranging from 2.87 to $7.25 \mathrm{ct}$ ) yielded refractive index readings of 1.52 , which, given that these are spot readings, is consistent with published R.I. values for afghanite $\left(\mathrm{n}_{\mathrm{o}}=1.522-1.528, \mathrm{n}_{\mathrm{e}}=1.528-1.533\right.$; $\mathrm{R}$. V. Gaines et al., Dana's New Mineralogy, John Wiley \& Sons, New York, 1997, p. 1634). The hydrostatic specific gravity ranged from 2.52 to 2.56 , with one cabochon giving a 2.60 value. The S.G. value reported in the literature is 2.55-2.65 (Gaines et al., 1997), and the slightly low reading of some of the samples is probably due to variable amounts of lazurite inclusions, which were present in all of our samples. In addition, inclusions of calcite and pyrite were identified with Raman analysis in some of the samples. In the previously published descriptions of afghanite, no mention was made of any inclusions.

To the unaided eye, the samples appeared translucent light blue; the mineral is described in the literature as "bluish" to colorless (Gaines et al., 1997). All the polished cabochons we examined contained numerous intense blue inclusions of lazurite that certainly added color to their host. As shown in figure 9, the lazurite inclusions also gave the polished cabochons a speckled appearance. With magnification, the irregularly shaped lazurite inclusions stood out in high relief due to their color (figure 10), while the (essentially colorless) calcite inclusions were much harder to see. It is not clear how much of the blue color in these afghanites is derived from the deep blue inclusions, and how much is actually intrinsic to the mineral.

John I. Koivula (jkoivula@gia.edu) and Maha Tannous GIA Gem Laboratory, Carlsbad 


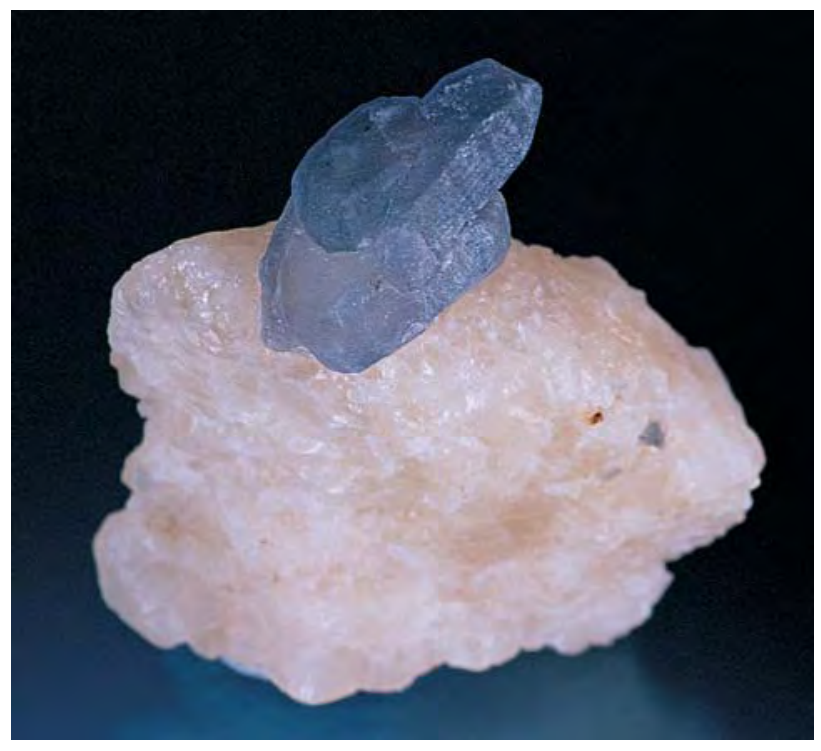

Figure 7. This 23-mm-long crystal of afghanite on calcite is from Badakhshan Province, Afghanistan. GIA Collection no. 30110; photo by Maha Tannous.

Blue beryl discovery in Canada. In August 2003, an unusually dark blue beryl was discovered in Canada's Yukon Territory by Bill Wengzynowski (Archer Cathro \& Associates, Vancouver, British Columbia; figure 11) and one of these contributors (LAG). Mr. Wengzynowski also is credited with the 1998 discovery of the Regal Ridge emerald deposit in the Yukon Territory, which is $\sim 100 \mathrm{~km}$ eastsoutheast of the blue beryl occurrence. These efforts were financed by True North Gems Inc. of Vancouver. The new gem is noteworthy for its dark blue color and strong dichroism, and is being referred to as "True Blue" beryl.

One of the contributors (WRR) visited the True Blue

Figure 9. These three cabochons of afghanite (2.87, 3.00 , and $3.26 \mathrm{ct}$ ) are speckled with inclusions of lazurite. Courtesy of Dudley Blauwet; photo by Maha Tannous.

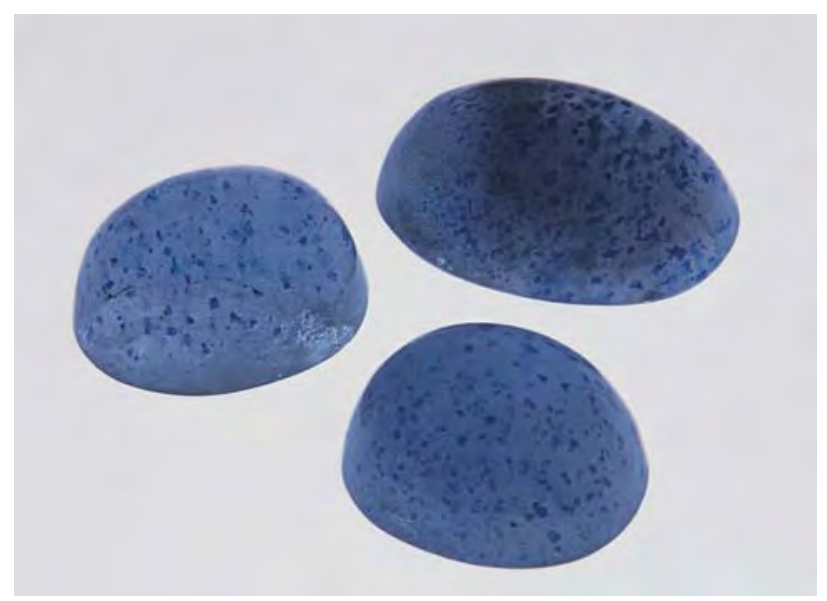

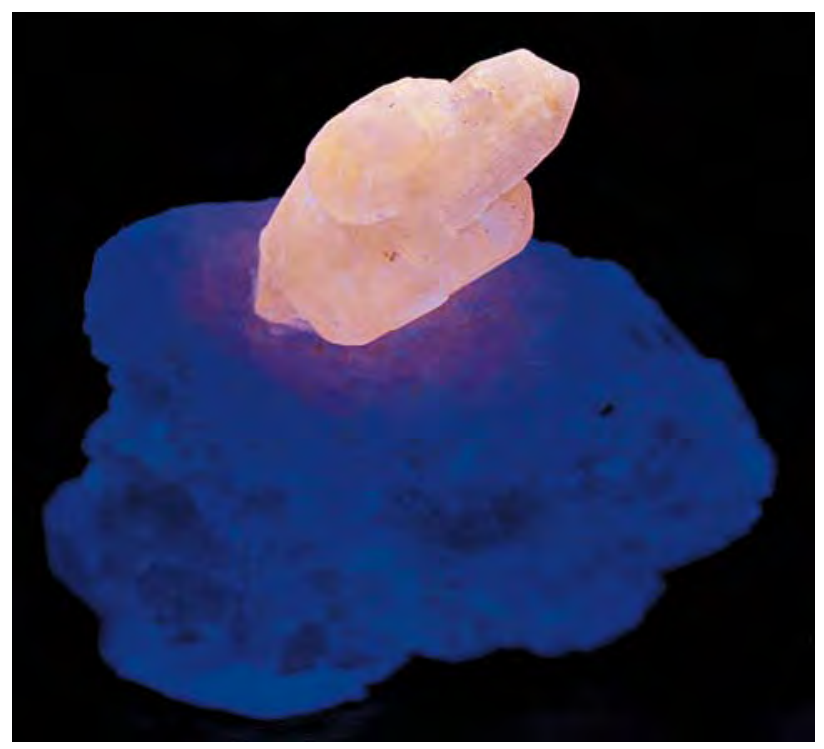

Figure 8. On exposure to long-wave UV radiation, the afghanite crystal in figure 7 fluoresced a strong, bright orange. Photo by Maha Tannous.

property shortly after it was discovered. The beryl occurs in a swarm of closely spaced quartz-carbonate-tourmaline veins (figure 12) that cut a Mississippian-age (320 million years) fluorite-bearing syenite stock. The veins range from 0.5 to $20 \mathrm{~cm}$ thick, and locally comprise up to $30 \%$ of the rock overall. The vein zone measures $700 \times 200 \mathrm{~m}$ in outcrop at the surface, and is exposed over an elevation range of $100 \mathrm{~m}$. Within this area, more than 100 individual occurrences of the beryl have been found on the surface.

In September 2003, True North Gems Inc. hand collected $65 \mathrm{~kg}$ of samples from outcrop in the vein zone,

Figure 10. With magnification, the irregular shape of the lazurite inclusions is apparent. These inclusions are at least partially responsible for the light blue color of their afghanite host. Photomicrograph by John I. Koivula; magnified 15×.

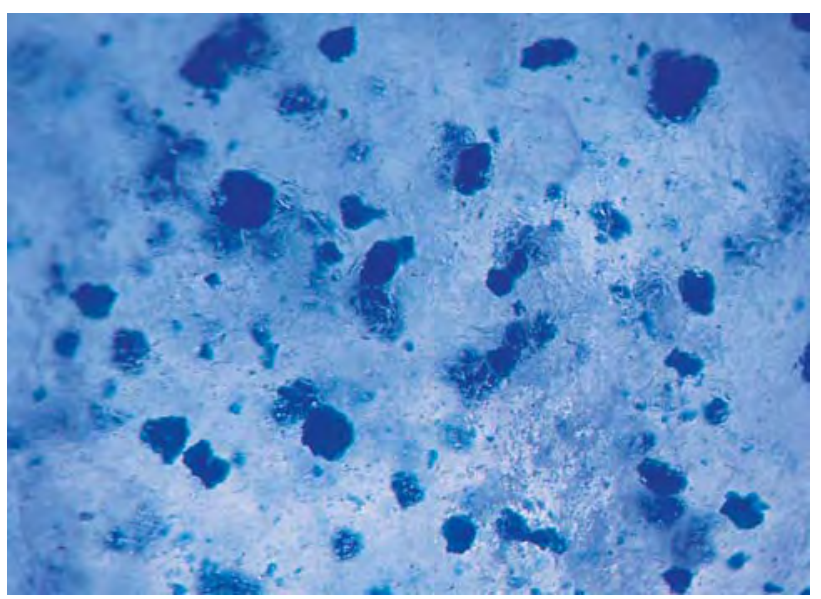




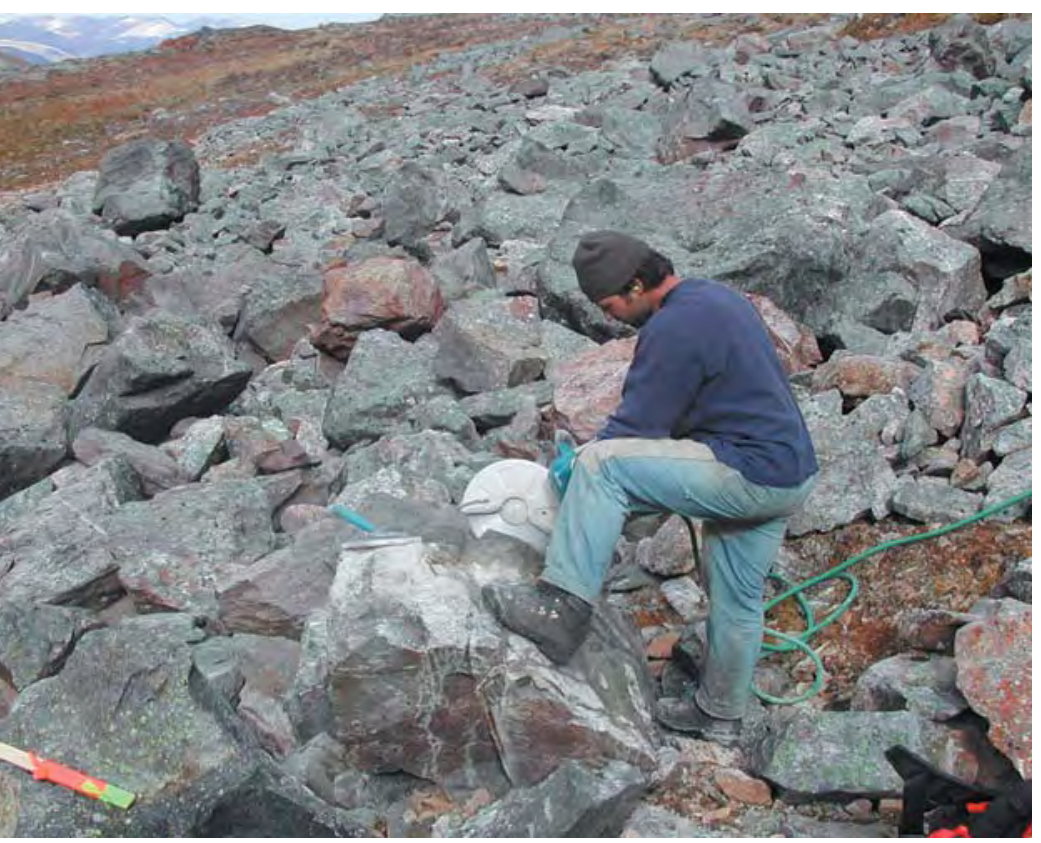

Figure 11. In August 2003, dark blue beryl was discovered in a remote area in the Yukon Territory of Canada. Here, that same month, Bill Wengzynowski uses a diamond saw to remove a beryl-bearing sample from a boulder at the deposit. Photo by Lee Groat.

which contained 57.9 grams of blue beryl. Individual crystals ranged up to $38 \mathrm{~mm}$ long and $11 \mathrm{~mm}$ in diameter. Five stones have been faceted thus far (figure 13): two elongated emerald cuts $(0.82$ and $0.79 \mathrm{ct})$ and three round brilliants $(0.06-0.11 \mathrm{ct})$. Prior to cutting, the pieces of rough were stabilized with Epo-Tek 301 epoxy. The stones were resinimpregnated again after preforming, and then once more, if needed, after faceting. The hue is maintained at exception-

Figure 13. Gemological properties were obtained on these samples of the dark blue beryl (0.06-0.82 ct). Courtesy of True North Gems Inc.; photo by Maha Tannous.

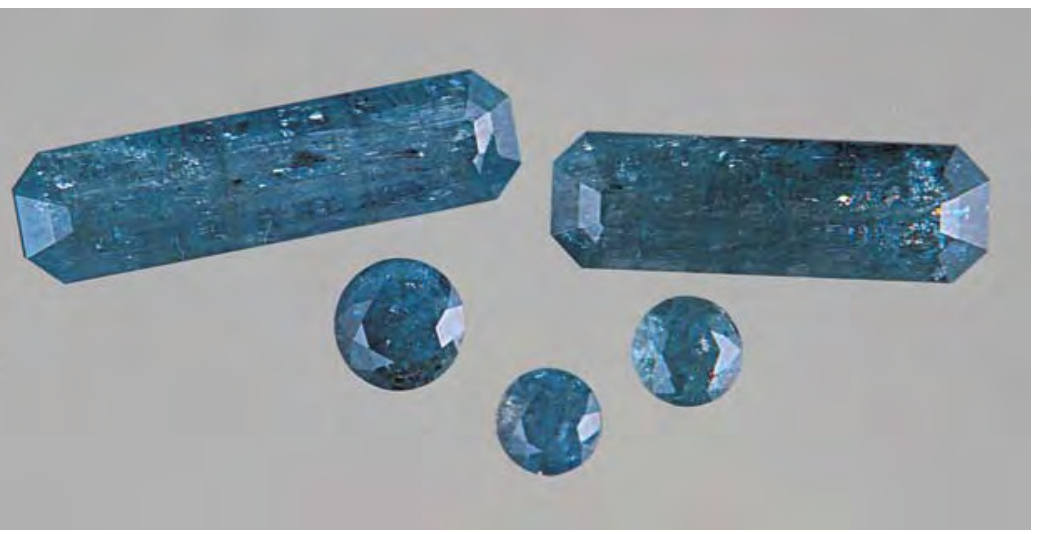

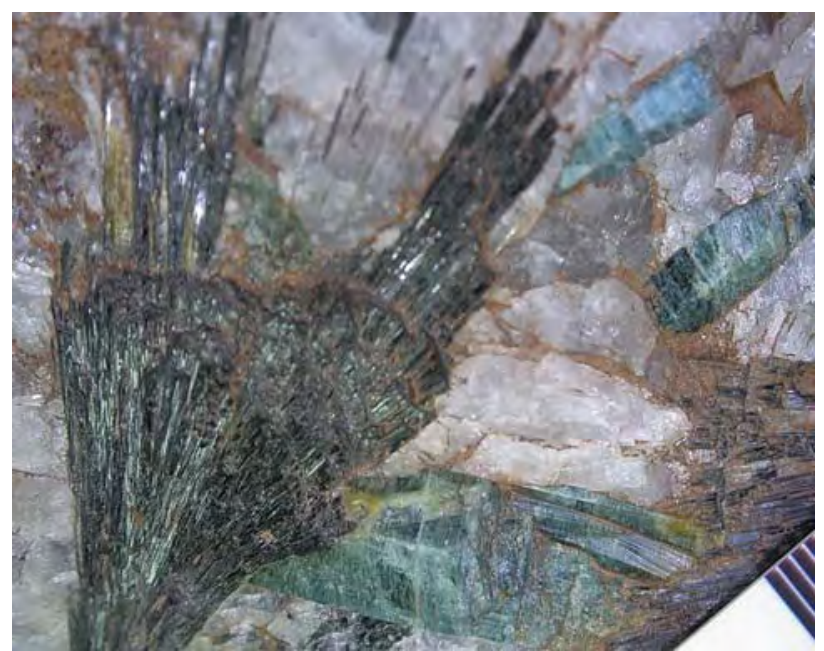

Figure 12. The dark blue beryl is hosted by veins containing quartz-carbonate-tourmaline assemblages. The bars on the ruler are millimeters; photo by David Turner.

ally small sizes for aquamarine (e.g., in the $1 \mathrm{~mm}$ round brilliants). The main constraints on the size of the stones faceted to date are the abundant fractures present in the material gathered from the surface, and the typically small diameter of the crystals.

The five faceted samples were examined by one of us (EPQ) at GIA, and the following properties were obtained: color-dark grayish greenish blue, with strong dichroic colors of deep blue to violetish blue and pale greenish blue to near colorless; diaphaneity-semitransparent to translucent; R.I. $-\mathrm{n}_{\mathrm{o}}=1.597-1.601, \mathrm{n}_{\mathrm{e}}=1.589-1.594$; birefringence0.008-0.009; S.G. of the two larger stones (measured hydrostatically) -2.78 and 2.79; Chelsea color filter reactionnone; fluorescence-inert to long- and short-wave UV radiation; and only general absorption to approximately 430 $\mathrm{nm}$ was observed with the desk-model spectroscope.

Microscopic examination revealed that all five samples were fairly heavily included, which significantly affected their transparency. Internal features included fractures, "fingerprints," growth tubes, two-phase fluid-and-gas inclusions, transparent near-colorless quartz crystals (identified with Raman spectroscopy), and evidence of clarity enhancement; one stone had parallel planar clouds. One of the small stones had a surface-reaching inclusion that was surrounded by a thin layer of a dark brown submetallic material. With Raman analysis, the interior portion was identified as a carbonate (probably siderite) and the surrounding material was identified as pyrrhotite.

Seven fragments of the beryl, ranging from deep blue to medium blue, were chemically analyzed by electron microprobe by one of us (LAG) at the University of British Columbia. These samples showed relatively high iron contents, ranging from 1.54 to $5.81 \mathrm{wt}$ \% FeO. The highest Fe content was found in the darkest blue sample, and surpasses the highest value for Fe in beryl that these con- 
tributors are aware of: 4.69 wt.\% Fe oxides for a "bluish" beryl from Arizona (W. T. Schaller et al., "An unusual beryl from Arizona," American Mineralogist, Vol. 47, 1962, pp. 672-699). The analyses also showed relatively high concentrations of $\mathrm{Na}$ and $\mathrm{Mg}$, and traces of $\mathrm{K}, \mathrm{Ca}, \mathrm{Sc}$, $\mathrm{Ti}, \mathrm{V}, \mathrm{Cr}, \mathrm{Mn}$, and Cs.

Polarized Vis-NIR absorption spectra (figure 14) of a deep blue, 0.68-mm-thick sample were recorded at the California Institute of Technology by GRR. The spectrum taken with light polarized parallel to the c-axis was dominated by a strong, wide band centered at about $850 \mathrm{~nm}$. With light polarized perpendicular to the c-axis, this band was weak. The difference in absorption between these two orientations accounts for the strong dichroism shown by this beryl. The spectroscopic features indicate that iron is the chromophore responsible for the blue color.

There are two distinct varieties of blue beryl: aquamarine and Maxixe. In the material studied here, we observed that the lighter pleochroic color (pale greenish blue to near colorless) was carried on the ordinary ray (viewed with polarized light down the optic axis.) This is typical of aquamarine and not of the deep blue Maxixe beryl, where the colors are reversed and carried on opposite rays. Aquamarine sometimes has a spectrum that is visible (but not pronounced) with a desk-model spectroscope, comprising a line at $427 \mathrm{~nm}$ and occasionally a weak band at $456 \mathrm{~nm}$, whereas Maxixe beryl typically has a series of six bands between 550 and 695 $\mathrm{nm}$. None of the lines commonly seen in Maxixe beryl were found in the five faceted samples, but the general absorption to $430 \mathrm{~nm}$ may be due to the aquamarine $427 \mathrm{~nm}$ band (related to iron). The R.I.'s recorded for this material were a bit higher than those previously recorded for aquamarine $\left(\mathrm{n}_{\mathrm{o}}\right.$

Figure 14. The Vis-NIR absorption spectra of the dark blue beryl are strongly polarized. When the beam was polarized parallel to the c-axis, the spectrum was dominated by a strong, wide band at about $850 \mathrm{~nm}$. Relatively little absorption was recorded when the beam was polarized perpendicular to the c-axis.

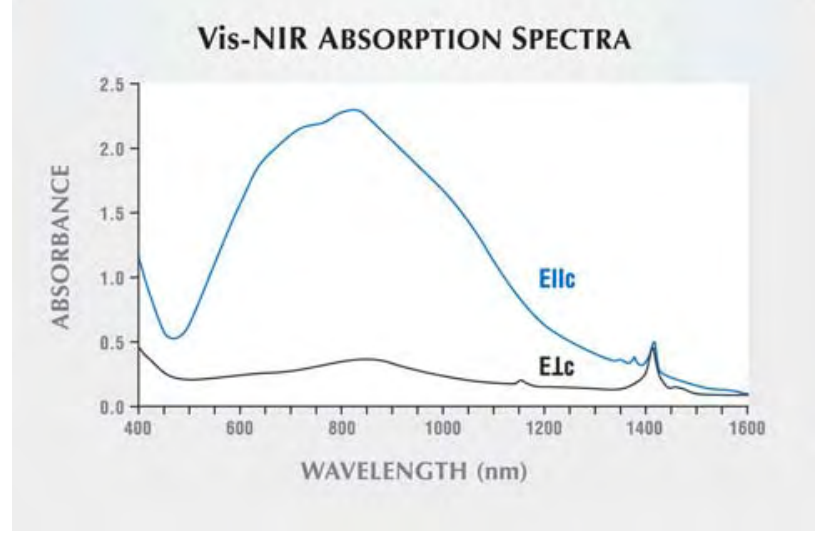

$=1.572-1.590$ and $\left.n_{e}=1.567-1.583\right)$, whereas the S.G. values of the two samples tested fell within the reported range for aquamarine, 2.66-2.80 (R. Webster, Gems, ButterworthHeinemann, Oxford, England, 1994, p. 124).

William R. Rohtert (william.rohtert@gte.net) Hermosa Beach, California Elizabeth P. Quinn GIA Gem Laboratory, Carlsbad Lee A. Groat

University of British Columbia Vancouver, British Columbia, Canada

George R. Rossman California Institute of Technology Pasadena, California

Gem-quality corundum from Colombia: Localities and inclusions. Although Colombia is well-known for producing fine emeralds, for years the country has also been a modest producer of ruby and sapphire (see, e.g., P. C. Keller et al., "Sapphire from the Mercaderes-Río Mayo area, Cauca, Colombia," Spring 1985 Gems «) Gemology, pp. 20-25, and the Fall 2000 Gem News section, p. 268). The gem corundum has been mined from alluvial deposits on both sides of the Río Mayo, which forms part of the border between the departments of Cauca and Nariño. This contributor recently completed a detailed study of rubies and sapphires from four mining areas in Colombia, which included 41 polished stones and nearly 2,800 pieces of rough obtained from several sources (see J. M. Duroc-Danner, "A study of Colombian corundum," Diplôme d'Université de Gemmologie, University of Nantes, France, 2002, 217 pp.). Among these samples, some of which are shown in figure 15, were rubies (eight polished and one minute piece of rough) and sapphires of various colors (including multicolored and change-ofcolor stones). Following is a brief summary of these

Figure 15. This 6.24 ct ruby cabochon, 2.58 ct oval multicolored sapphire (pale blue, gray, and pink), and 2.19 ct marquise sapphire from Colombia formed part of the study samples. Photo by J.-M. Duroc-Danner.

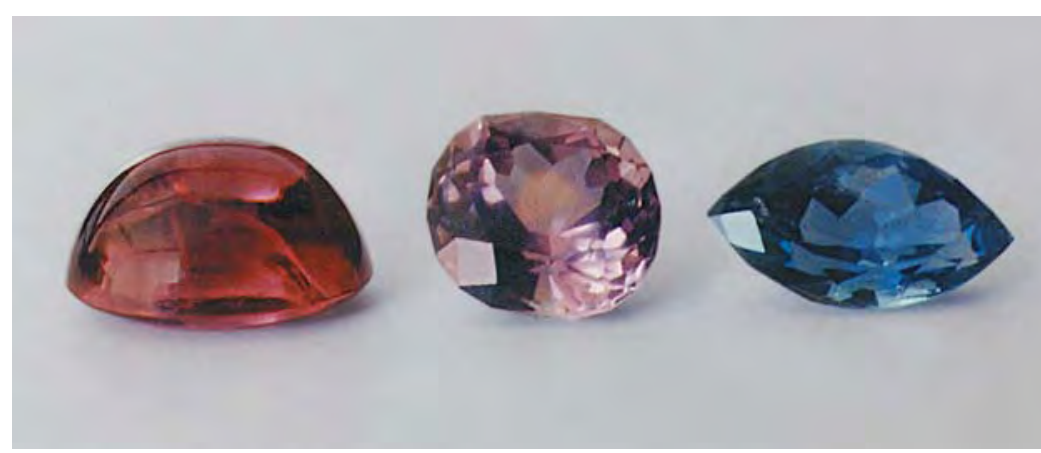




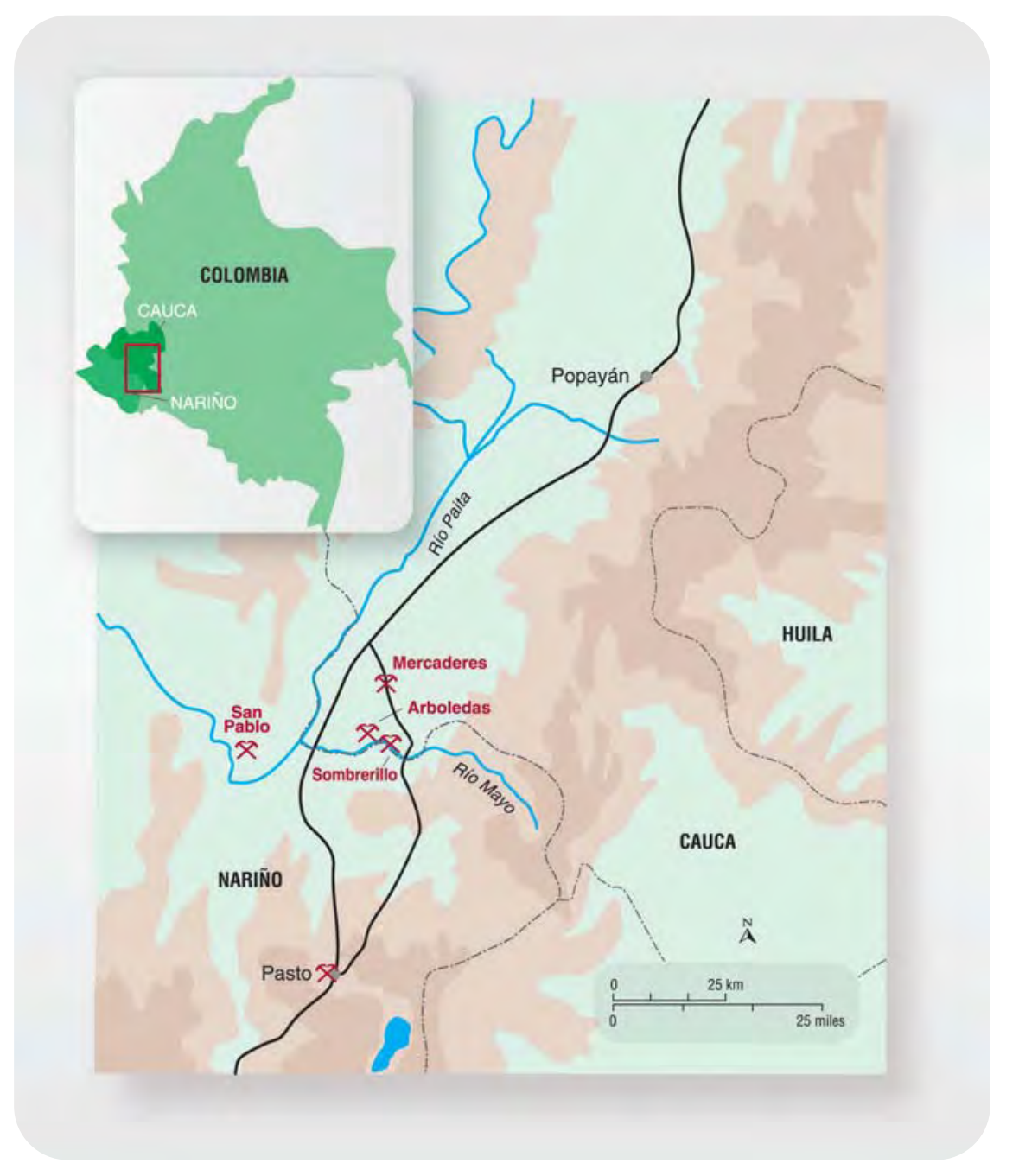

Figure 16. In southwestern Colombia, ruby and sapphire are mined from four principal regions within the Cauca, Nariño, and Caquetá Departments. Caquetá is located just east of the map area shown. After Keller et al. (1985).

Colombian localities and inclusions identified in the gem-quality corundum studied.

All of the corundum deposits reported to date are located in southwestern Colombia, in four principal regions of three departments - Cauca, Nariño, and Caquetá (figure 16):

1. Cauca-Near the village of Mercaderes (at Quebrada Senegetas, La Maria ranch, Río Sangandinga), close to the village of Sombrerillo and hamlet of Sombrerillos (at Quebrada del Rubí and Quebrada Limoncito), and in the region of Arboledas village (at Quebrada Las Cañadas, Quebrada Paloverde, Quebrada Honda, Quebrada Monserrate, Quebrada Monteoscuro, and Alto La Cañada).

2. Along the border of the Cauca and Nariño Departments-Together with garnet and amethyst in the Río Mayo.

3. Nariño-At San Pablo (about $20 \mathrm{~km}$ northwest of the Doña Juana volcano) and near Pasto $(8 \mathrm{~km}$ east of the Galeras volcano).

4. Caquetá-From sands of the Río Platoyaco, a tributary of the Río Caquetá.
Although production figures are not available, most of the corundum appears to have come from Quebrada del Rubí, Quebrada Paloverde, Quebrada Honda, Quebrada Monserrate, and Quebrada Monteoscuro. Due to the political instability and guerrilla activities in the region, there are no organized mining activities. Rather, the material is collected by local people using artisanal methods.

In both the rough and faceted corundum samples, various inclusions were observed with the microscope and identified using Raman spectroscopy. Zircon was common; it typically occurred as doubly terminated colorless crystals (figure 17), with or without tension fractures. Occasionally seen were dark, opaque zircon inclusions with associated tension cracks. Rutile formed black or dark brown to red doubly terminated crystals that sometimes showed twinning. Some stones contained small, densely woven nests composed of very short needles that were probably also rutile; these appeared similar to those found in corundum from Myanmar. Boehmite also was common, typically occurring as white needles lying at the junction of intersecting twin planes; polysynthetic twinning was present in nearly all of the rough corundum examined. Boehmite also 


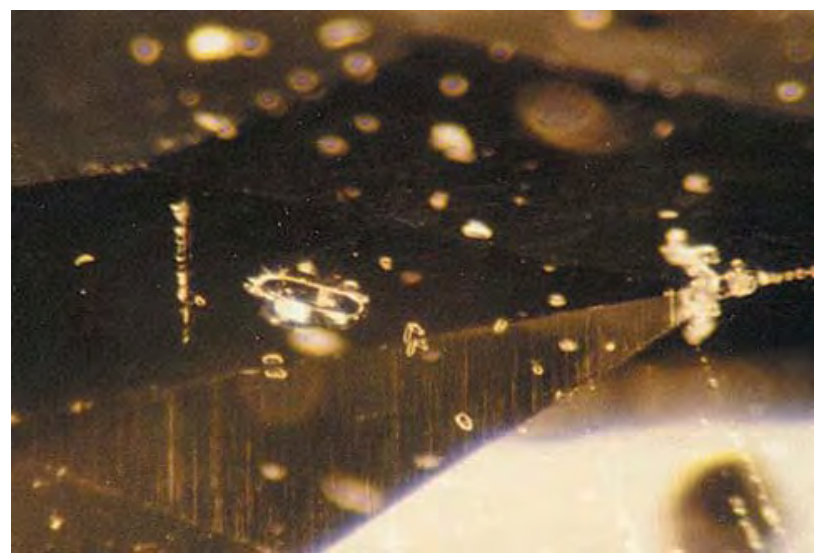

Figure 17. Zircon inclusions were common in the Colombian corundum, and often formed doubly terminated, colorless crystals. Photomicrograph by J.-M. Duroc-Danner; magnified 40×.

was seen as coarse needles intersecting in three directions, similar to those found in Thai rubies, and as fine white needles in a scaffold-like arrangement, as observed in some East African corundum. Pinpoint inclusions (zircon, rutile, and apatite, among others) were present in many of the stones. Larger apatite inclusions were seen in some samples, and plagioclase feldspar occurred in abundance in one specimen.

In addition to mineral inclusions, partially healed fractures and internal stress fractures were occasionally observed, as were a few "fingerprints," some of which were similar to those encountered in Sri Lankan sapphires. Pseudohexagonal growth zoning was visible as distinct cloud-like zones in a few samples (figure 18). Many of the stones were color zoned, particularly with pronounced areas of yellow color.

Consistent with the gemological properties, the chemical composition and spectroscopy (UV-Vis and FTIR) of the samples demonstrated that most of the corundum was of basaltic origin. However, a small number had characteristics that were consistent with a non-basaltic source. Since many of the characteristics shown by the Colombian corundum overlap those from other world localities, they could not be separated according to geographic origin.

Jean-Marie Duroc-Danner (durocdanner@bluewin.ch) Gemgrading, Geneva, Switzerland

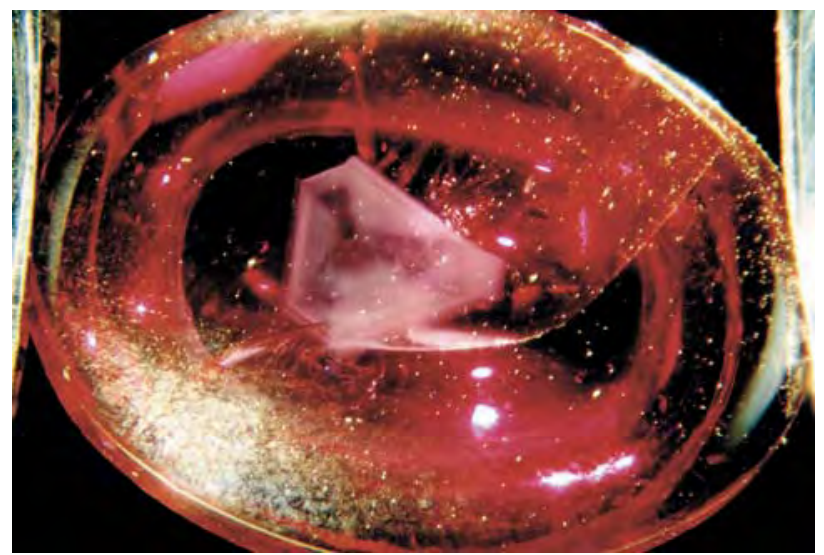

Figure 18. Pseudohexagonal growth zoning is clearly visible in this $6.24 \mathrm{ct}$ Colombian ruby. Photomicrograph by J.-M. Duroc-Danner; magnified 12x.

Emeralds from Madagascar with strong blue/green dichroism. M. Guillet, a mineral dealer from St. Nazaire, France, brought to this contributor's attention a new production of emeralds from Madagascar (the exact locality was not disclosed to him). Most of the over 200 carat parcel was composed of small, commercial quality, fairly included polished stones up to about $2 \mathrm{ct}$.

Gemological properties were obtained on five of the emeralds. The R.I. values were 1.585-1.592, specific gravity (determined hydrostatically) was 2.75 , and the stones displayed a uniaxial negative optic figure. All were inert to ultraviolet radiation, and showed no reaction to the Chelsea filter. Most remarkable was their very strong dichroism: from yellowish green to dark "aquamarine" blue (figure 19). The relatively high R.I. and S.G. values are reminiscent of emeralds from Zimbabwe and Zambia, whereas the strong blue/green dichroism was previously found only in Nigerian emeralds (see H. A. Hänni, "Considérations terminologiques au subjet des émeraudes du Nigéria de couleur bleu-vert," Revue de Gemmologie, No. 113, 1992, pp. 2-4).

Editor's note: An emerald represented as originating in Goiás State, Brazil, that shows a noticeably blue color component is reported in the Lab Notes section of this issue (p. 317).

Figure 19. Strong dichroism is evident in this emerald, which reportedly is from a new locality in Madagascar. Photomicrographs by John I. Koivula; magnified $12 \times$.
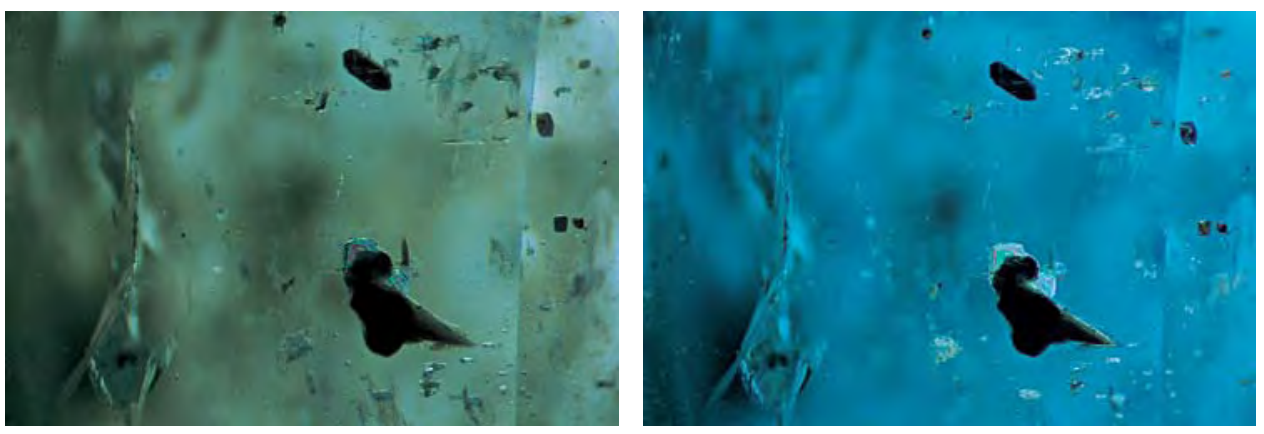


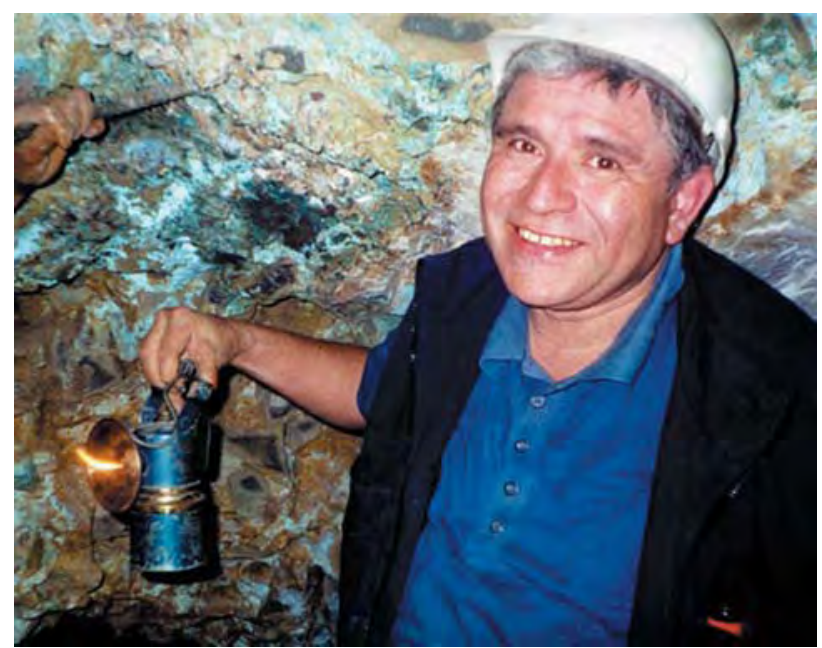

Figure 20. At the Lily mine in Peru, blue opal is mined from underground workings, where it forms in association with calcite, chalcedony, quartz, and chalcotrichite. Carbide lamps are used for lighting the tunnels, as shown by mine owner Felix Rocha. Courtesy of Roxanne Kremer.

Peruvian blue opal. Small quantities of attractive blue opal from the Andes Mountains of Peru have been seen in the gem trade for years (see Summer 1991 Gem News, pp. 120-121, and Spring 1994 Lab Notes, pp. 43-44). Recently we were provided with a notable sample and updated information on mining and production of this opal from Roxanne Kremer of Collectors Co., Rosemead, California, who visited Peru in November 2003. Ms. Kremer reported that there are two principal sources of blue opal in Peru: the Acari and Lily mines. The Acari mine, located in the department of Arequipa, has been worked for two decades.

Figure 21. This $17.58 \mathrm{ct}$ blue opal reportedly is an example of the finest material produced from the Lily mine in Peru. Courtesy of Roxanne Kremer; photo by Maha Tannous.

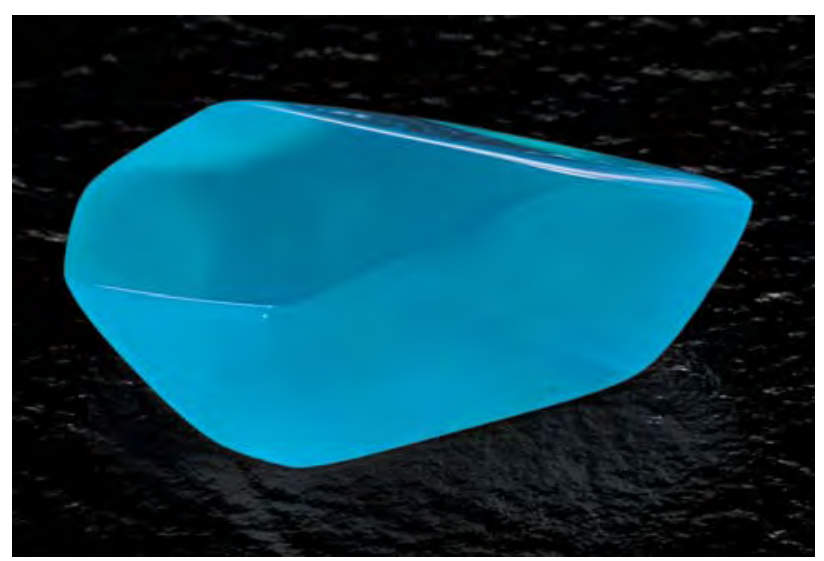

The Lily mine, in the department of Ica, has produced blue opal for approximately 10 years.

According to Ms. Kremer's sources at the Lily mine, about 10 tonnes of opal are produced there every 2-3 months, but only $1-2 \mathrm{~kg}$ are gem quality. The blue opal forms in association with calcite, chalcedony, quartz, and chalcotrichite (a variety of cuprite), and is mined from underground workings (figure 20) with small charges of dynamite. Although pieces of blue rough up to $100 \mathrm{~kg}$ have been recovered, only small areas have the purity and color that are appropriate for jewelry use. The low-grade material is carved in China and Hong Kong, while the gem-quality opal is polished locally in Peru.

Ms. Kremer loaned an attractive $17.58 \mathrm{ct}$ polished freeform opal (figure 21) from the Lily mine to GIA for examination. The following gemological properties were obtained by one of us (EPQ): color-slightly mottled, greenish blue; diaphaneity-semitransparent to translucent; R.I.-1.45 by the spot method; S.G.-2.11; Chelsea filter reaction-none; luminescence-very weak bluish green fluorescence to long- and short-wave UV (with a slightly stronger reaction to the former) and no phosphorescence. With the desk-model spectroscope, only a cutoff was observed at around $650 \mathrm{~nm}$. Microscopic examination revealed yellowish brown and wispy white clouds, small yellowish orange crystals, small dark metallicappearing crystals (possibly hematite), and transparent near-colorless crystals (probably quartz). The properties of this sample were consistent with those reported in the Gems \& Gemology entries listed above for similar blue opal from Peru.

\section{Elizabeth P. Quinn (equinn@gia.edu)} GIA Gem Laboratory, Carlsbad $\mathrm{oBML}$

Some interesting pearls from the North American West Coast. Although they are not common on the retail market, occasionally in the GIA Gem Laboratory we see natural and cultured pearls from North America, such as those from the Pteria sterna and Pinctada mazatlanica oysters in Mexico's Gulf of California, as well as the natural and cultured freshwater pearls from the Unionidae mussels of Tennessee, Mississippi, Texas, Ohio, and other states. We also are fortunate to see natural abalone pearls from the coast of North America. These currently originate predominantly from the green abalone (Haliotis fulgens) and the pink abalone $(H$. corrugata). Occasionally, pearls from the red abalone ( $H$. rufescens) and the black abalone $(H$. cracherodii) are seen, but they are usually from older collections as these abalones have become more scarce and are no longer fished commercially.

Jeremy Norris of Oasis Pearl in Albion, California, recently loaned GIA some of his rare-pearl inventory for examination. These included two pen shell pearls (one brown and one black) from the Pacific coast of Baja 


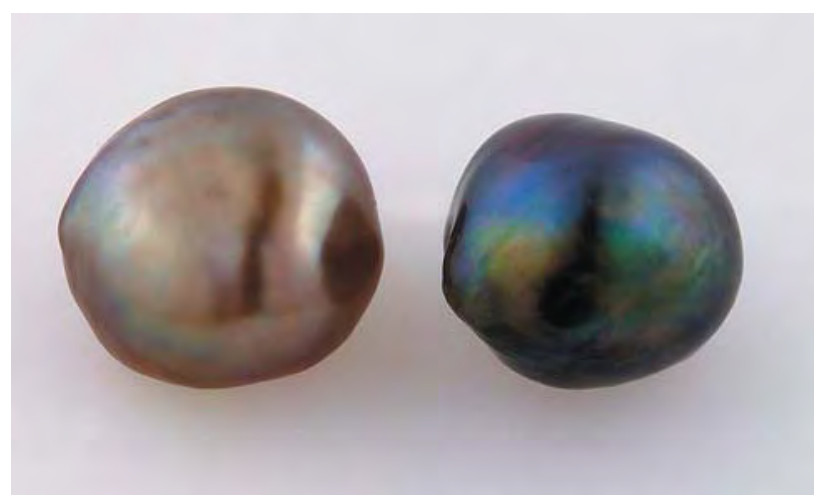

Figure 22. These pen shell pearls $(7.6 \times 7.1 \times 4.8 \mathrm{~mm}$ and $7.3 \times 6.7 \times 6.0 \mathrm{~mm}$ ) originate from the Pacific coast of Baja California, Mexico. Photo by C. D. Mengason.

California, Mexico, as well as two unusual abalone pearls and a nacreous pearl from a turban snail.

The pen shell pearls (figure 22), which probably came from Atrina maura or Pinna rugosa, had an interesting nacre structure when viewed with magnification. Instead of the usual overlapping platelets with a stepped appearance, the nacre appeared as a network of tiny shallow elongated rectangular "webs." The different appearance of the nacre in pen shell pearls from the Pinna species has been explained by the fact it is not constructed of concentric layers of nacre, but rather of numerous small prisms arranged around the center (see J. Taburiaux, Pearls: Their Origin, Treatment 4 Identification, 1985, Chilton Book Co., Radnor, Pennsylvania). Unfortunately, the structure was too subtle to show clearly on a photograph.

Each of the abalone pearls was unusual in shape and appearance (figure 23). The nearly round shape of the 29.37 ct freely formed pearl $(18.4 \times 17.7 \times 17.4 \mathrm{~mm})$ was notable, since abalones' strong muscular bodies typically deform pearls into baroque shapes as they grow. To obtain a nearly round abalone pearl is quite rare.

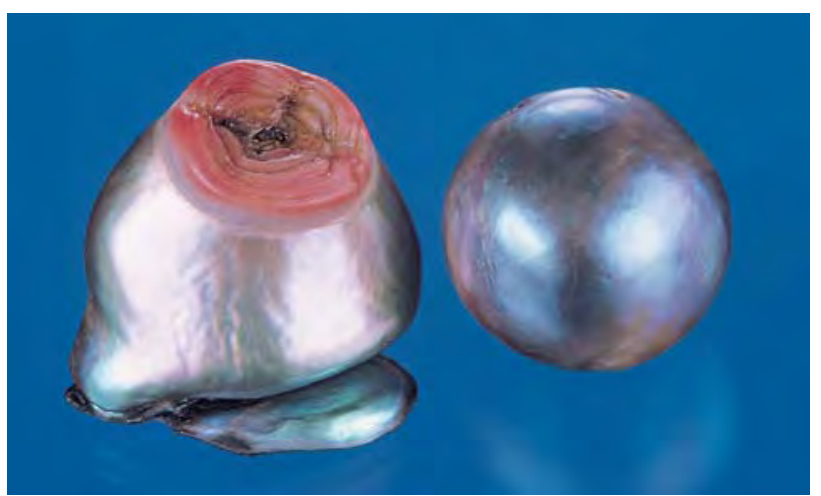

Figure 23. These abalone pearls (40.13 and $29.37 \mathrm{ct}$ ) were unusual in shape, appearance, and growth structure. Photo by Maha Tannous.

The 40.13 ct abalone pearl $(23.5 \times 19.9 \times 18.0 \mathrm{~mm})$ was very unusual in that part of it had extruded through to the outside of the abalone shell during growth. External shell material was deposited on this end, creating a series of red ridges. The ridges were non-nacreous, and a band of irregularly arranged structural patches formed at the junction between the ridges and the nacre. The red ridges imparted an intriguing appearance, calling to mind a sea anemone or other natural creature. X-radiographs of both abalone pearls revealed that the nearly round pearl was partially hollow, and the ridged pearl was nearly solid.

One of the most interesting items provided by Mr. Norris was a 19.80 ct nacreous turban snail pearl $(22.9 \times$ $16.1 \times 10.9 \mathrm{~mm}$; figure 24), which was presumed to be from the wavy turban, Astraea undosa. It was the first such pearl this contributor had examined closely. The pearl was off-white, with high luster and orient, and exhibited striking iridescent colors similar to those seen in some North American freshwater pearls. The structure displayed an undulating wave-like pattern. The nacre was very smooth, resembling that of abalone. In numerous

Figure 24. This $19.80 \mathrm{ct}$ nacreous pearl (shown here in two views) originated from a turban snail. Photos by Maha Tannous.
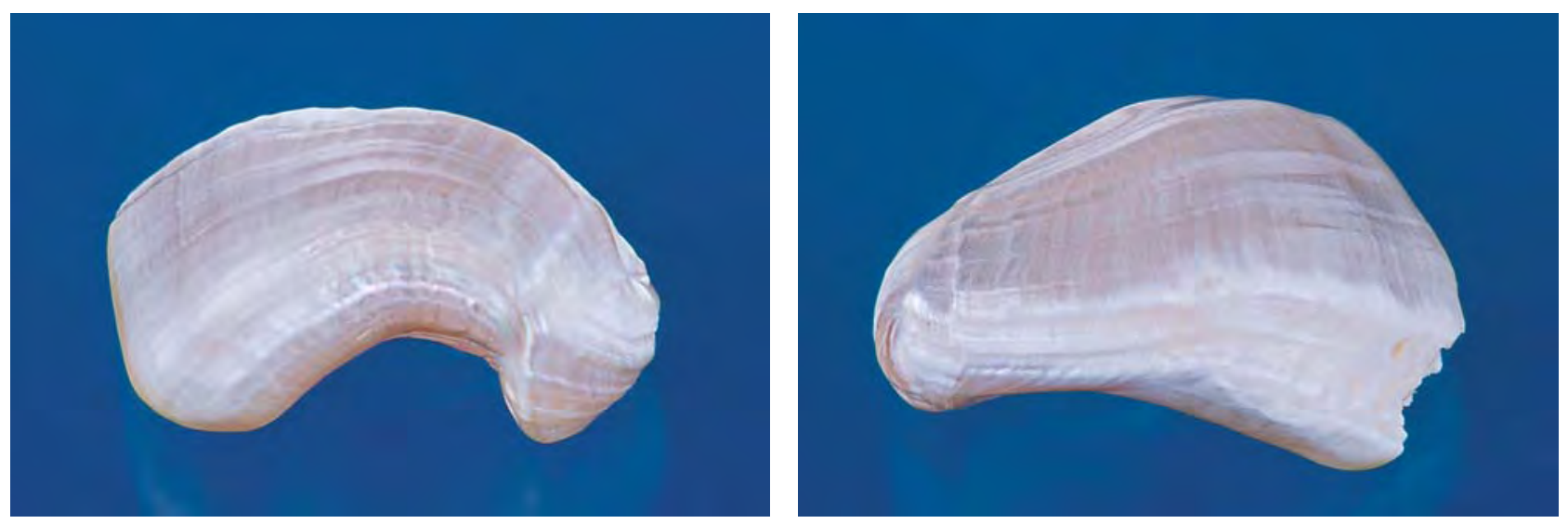


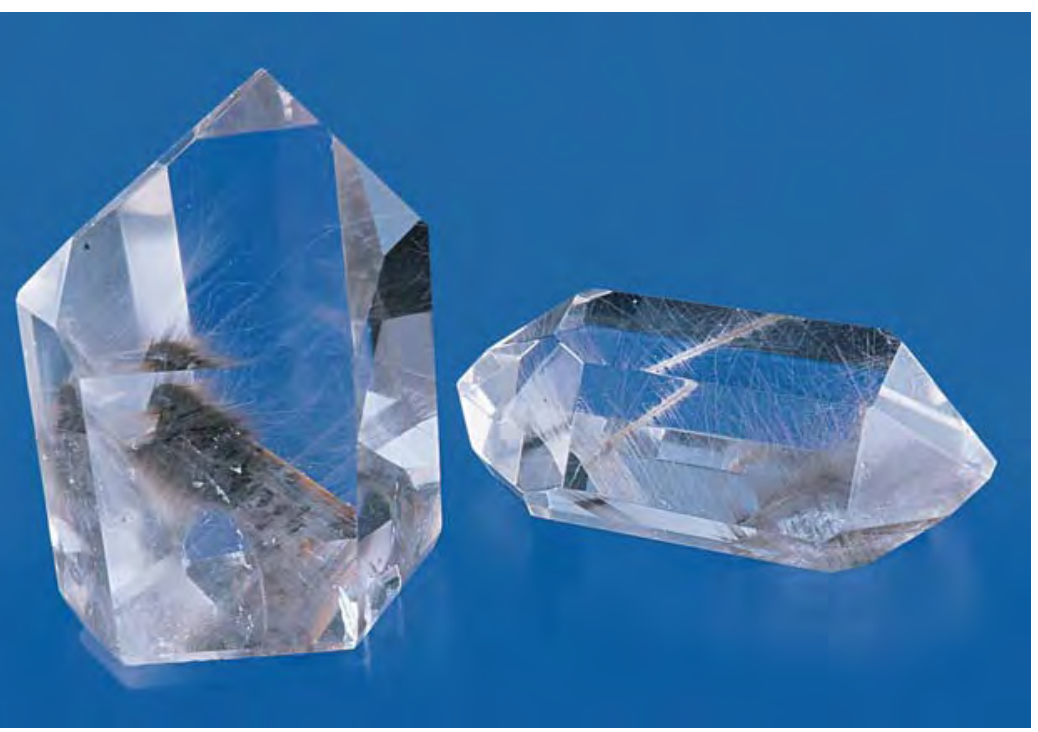

Figure 25. These two polished crystals of "platinum quartz" from Curvelo, Minas Gerais, Brazil, weigh 222.26 and $94.73 \mathrm{ct}$. The inclusions are composed of rutile and brookite. Photo by Maha Tannous.

areas on the pearl, the nacre was so smooth and glassy that it appeared to have a polished "wet" appearance; Mr. Norris said that this appearance and high luster was natural for this turban snail pearl.

CherylWentzell (cwentzell@gia.edu) GIA Gem Laboratory, Carlsbad

"Platinum quartz." Over the past several years, we have seen examples of rough and polished rock crystal and pale smoky quartz crystals, as well as polished free-form pieces

Figure 26. As identified by Raman analysis, slender needles of rutile are clearly visible extending from the underlying central crystal of brookite in this "platinum quartz" from Brazil. Photomicrograph by John I. Koivula; magnified $5 \times$.

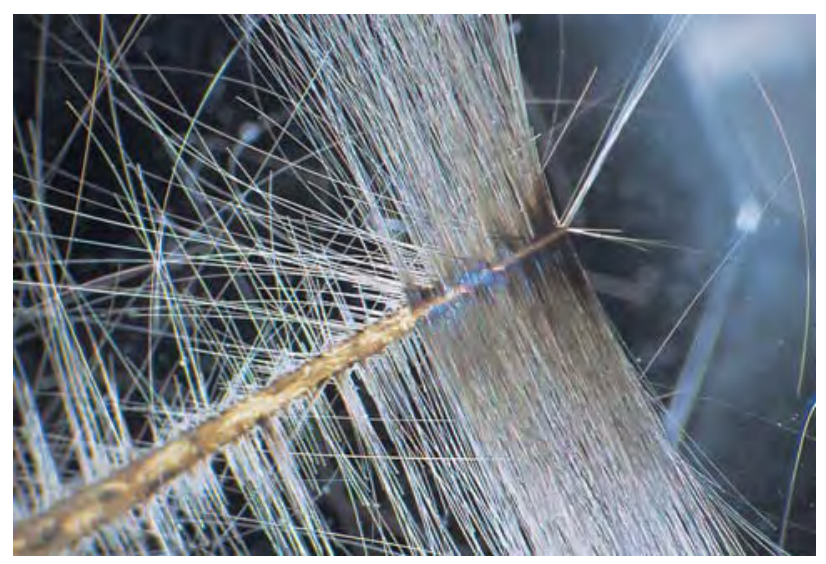

of quartz, that contain inclusions of silvery reflective rutile needles. The rutile inclusions in these pieces, all from Brazil, grow from and are oriented on light brown elongated blades of brookite, another titanium-oxide mineral.

Shortly after this material entered the marketplace, one of the present contributors (JIK) obtained a few specimens (see, e.g., figure 25) for photomicrography and inclusion analysis from Luciana Barbosa, of the Gemological Center in Belo Horizonte, Minas Gerais, Brazil, and two lapidaries/jewelry designers-Falk Burger of Los Alamos, New Mexico, and Kevin Lane Smith of Tucson, Arizona. Although the inclusion study was completed, the results were never published.

Then, at a recent jewelry trade show in New York, James Shigley, GIA director of Research (and Gems Gemology and GNI contributing editor), spoke with a supplier of the material, Ricardo Viana of Belo Horizonte, Brazil. Mr. Viana was marketing the material as "platinum quartz." He subsequently sent several specimens to Dr. Shigley, which were then provided to these contributors for gemological examination. Mr. Viana also informed us that the quartz reportedly is from Curvelo, in Minas Gerais. At about the same time, an additional sample of the material was provided by David Epstein of Precious Resources Ltda. in Teófilo Otoni, Brazil.

The inclusions in both the older and newer samples looked virtually identical in morphology, having a feathery to insectile appearance, and Raman analysis proved that they were indeed the same materials (rutile and brookite).

With magnification, the inclusions generally appeared as blades of light brown or tan brookite from which numerous slender silvery rutile crystals extended in more-or-less parallel arrangements. As shown in figure 26, in some samples the central blade of brookite was still apparent, while in others the rutile was so dense that the brookite nucleus could no longer be seen. More rarely, the brookite blades were clearly visible with only a sparse number of rutile fibers extending from them (figure 27). In these few samples, the precise orientation of the rutile on the brookite suggested that the rutile had grown epitaxially on the substrate. Since brookite is a lower-temperature form of titanium oxide (rutile is the higher-temperature variant), the presence of the associated oriented rutile suggests that as the inclusions (which are protogenetic to the host quartz) developed, the temperature increased so that rutile was preferred.

John I. Koivula and Maha Tannous

Some rare faceted gem materials. This contributor recently had the opportunity to examine specimens of three gem materials that are very rarely seen in faceted form: chlorargyrite, stolzite, and sulfoborite.

Chlorargyrite. Faceted silver minerals are perhaps the rarest of all collector gems (see figure 28). By far the most 
beautiful of them is deep red proustite, trigonal $\mathrm{Ag}_{3} \mathrm{AsS}_{3}$, which has been found as facetable crystals in Germany and the Czech Republic, among other locations. However, the best specimens are from Chanarcillo, Chile, and faceted stones from this locality have been seen in sizes up to 55.48 ct (Patricia Gray, pers. comm., 2003). Much less interesting is pyrargyrite, trigonal $\mathrm{Ag}_{3} \mathrm{SbS}_{3}$, which is usually red only in transmitted light; the best facetable crystals come from Colquechaca, Bolivia. Both proustite and pyrargyrite are light sensitive and should be kept in darkness.

Chlorargyrite (cubic $\mathrm{AgCl}$ ) is quite common in many silver deposits as small cubes or grains. This contributor recently examined seven faceted stones (see example in figure 28) up to $10 \mathrm{ct}$ that were cut from a single $1-\mathrm{cm}$ thick vein of massive translucent chlorargyrite. The $7 \times 5$ $\mathrm{cm}$ specimen came from Chanarcillo, and was probably found in the mid-19th century (R. B. Cook, "Famous mineral localities: Chanarcillo, Chile," Mineralogical Record, Vol. 10, No. 4, 1979, pp. 197-204). Cutting and polishing were very difficult because of chlorargyrite's very low hardness of 2 on the Mohs scale. The material also proved to be highly corrosive: The wheel used to facet the stones became so badly corroded it was useless a few days after cutting.

The faceted chlorargyrites were "creamy" yellow in color and had a waxy luster. According to the literature, the R.I. of chlorargyrite is 2.07 (R.V. Gaines et al., Dana's New Mineralogy, John Wiley \& Sons, New York, 1997, pp. 377-378). Specific gravity, measured hydrostatically, was 5.55. The stones examined showed anomalous interference colors under crossed polarizers, had no reaction to UV radiation, and displayed no visible spectrum in a handheld spectroscope. Because chlorargyrite is light sensitive (becoming darker with exposure to light), the stones should be kept in darkness.

Other silver-bearing minerals have been polished into gems, as well. Boleite, an Ag-Cu-Pb-chloride from Boleo, Mexico, may be faceted into small dark blue stones, and native silver embedded in calcite (e.g., from Canada and the Czech Republic) can be cut into cabochons.

Stolzite. Another extremely rare gem is stolzite, $\mathrm{PbWO}_{4}$ (figure 29). It is known only from a few localities; J. E. Arem mentions a few tiny bright orange faceted stones from Broken Hill, New South Wales, Australia (Color Encyclopedia of Gemstones, 1987, Van Nostrand Reinhold, New York, p. 181). It has also been grown synthetically for industrial applications at Turnov, Czech Republic (again, see figure 29). By far the best-known stolzite crystals were found between 1987 and 1991 in the Sainte Lucie mine in southern France (see S. Weiss, "Stolzit aus Sainte Lucie, Frankreich: Die grössten und besten Kristalle der Welt," Lapis, Vol. 27, No. 1, 2002, pp. 17-20; see also figure 30). These yellow-to-orange tabular crystals measured up to $8 \mathrm{~cm}$ across. Many of them had a

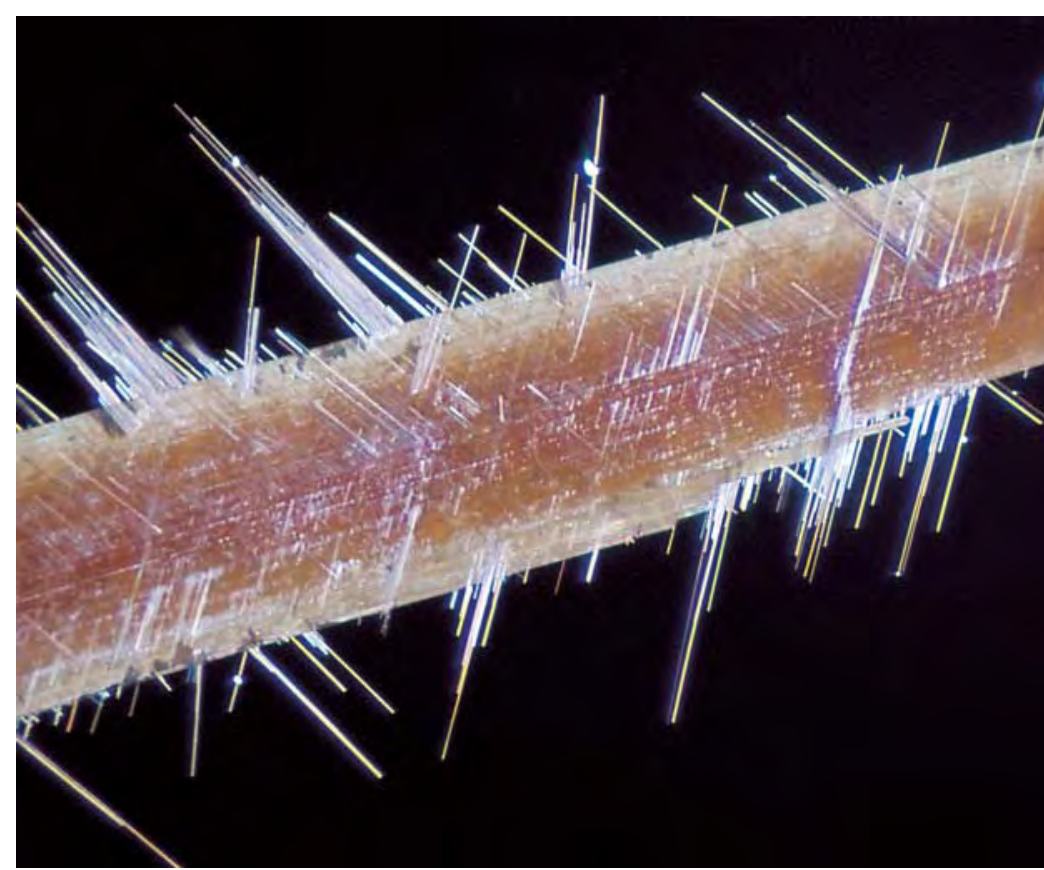

Figure 27. The precise orientation of rutile needles from the brown blade of brookite is apparent in this unusual example of "platinum quartz" from Brazil. Photomicrograph by John I. Koivula; magnified 10×.

semitransparent core that corresponded chemically to pure stolzite. The core was covered, sandwich-like, by almost opaque yellow layers of Mo-rich stolzite (i.e., containing a wulfenite component).

According to Gaines et al. (1997, pp. 1000-1001), the Mohs hardness of stolzite is 2.5-3, and the refractive index is very high: $2.18-2.27$. The three faceted stolzites from

Figure 28. These faceted silver minerals are among the rarest of collector stones. Shown here, from left to right, are a $5.22 \mathrm{ct}$ proustite from Germany, a $9.45 \mathrm{ct}$ chlorargyrite from Chile, and a 2.17 ct pyrargyrite from Bolivia. Photo by J. Hyrsl.

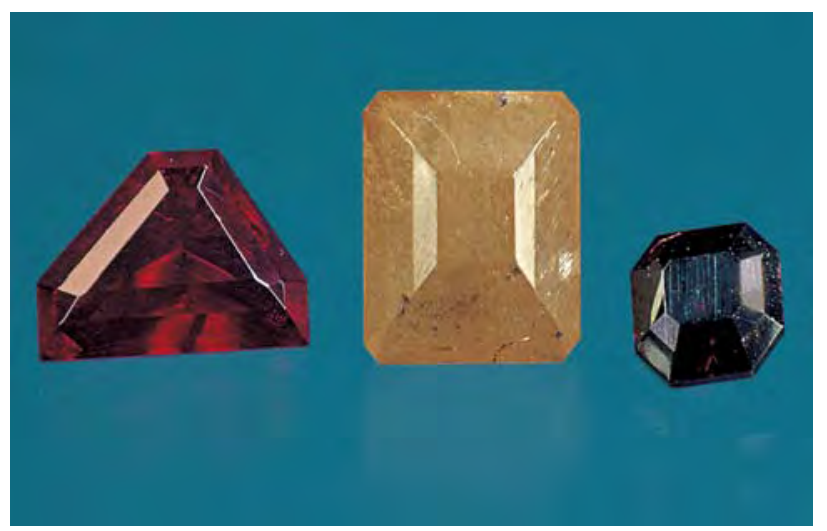




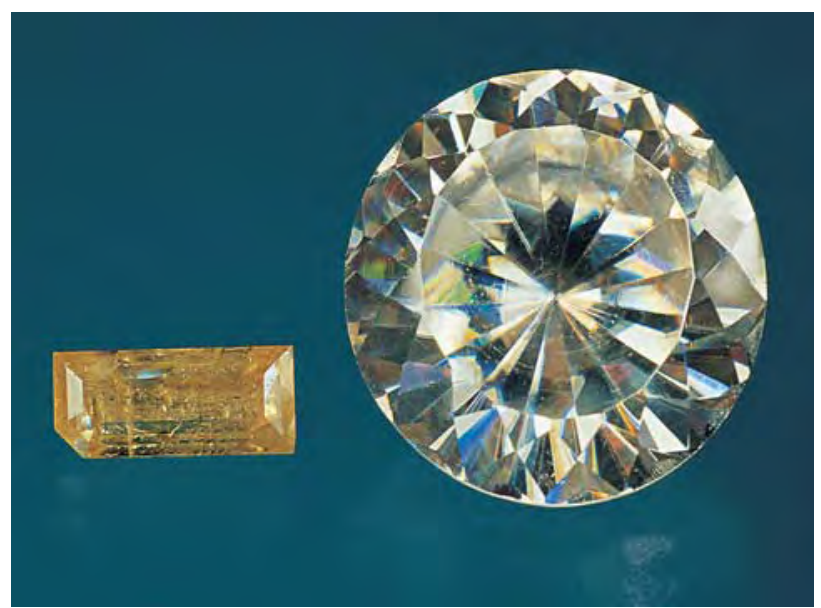

Figure 29. The $3.84 \mathrm{ct}$ faceted yellow stolzite shown here is from the Sainte Lucie mine in France; the 56.49 ct near-colorless round brilliant is a synthetic stolzite grown in the Czech Republic. Photo by J. Hyrsl.

France examined by this contributor $(0.76-3.84 \mathrm{ct})$ had a specific gravity of 8.23-8.32 (measured hydrostatically). The stones exhibited yellow fluorescence to short-wave UV radiation, and were inert to long-wave UV. They also showed two thin lines in the yellow region of the spectrum when viewed with a handheld spectroscope, and had a negative optic character.

Sulfoborite. Many rare minerals, especially sulfates and borates, are found at the Inder borate deposit on the north shore of the Caspian Sea in western Kazakhstan (I. V. Pekov and D. V. Abramov, "Boron deposit of the Inder and its minerals," World of Stones, Vol. 1, 1993, pp. 23-30). Small faceted examples of preobrazhenskite and kaliborite from Inder were described in the Summer 1995 Gem News section (pp. 129-130); the görgeyite in that entry was most likely from Inder as well.

Sulfoborite, $\mathrm{Mg}_{3} \mathrm{~B}_{2}\left(\mathrm{SO}_{4}\right)(\mathrm{OH})_{8}(\mathrm{OH}, \mathrm{F})_{2}$, has been found at Inder in several forms. The most beautiful are very rare prismatic water-clear crystals that are similar in shape to topaz and have been known to reach $5 \mathrm{~cm}$ long. This contributor obtained five faceted stones $(0.10-1.27 \mathrm{ct})$ and several crystals of sulfoborite (see, e.g., figure 31 ). Their measured refractive indices were 1.532-1.550, as compared to published values of 1.527-1.552 (Gaines et al., 1997, p. 566). Specific gravity, measured hydrostatically, was 2.44-2.46. The stones were inert to UV radiation, and no absorption lines were observed with a handheld spectroscope. The Mohs hardness was 4-4.5.

In addition to görgeyite, preobrazhenskite, kaliborite, and sulfoborite, many other rare minerals have been found at Inder, some of them in transparent crystals suitable for faceting, especially hydroboracite, pinnoite, inyoite, and inderborite.

Jaroslav Hyrsl (hyrsl@kuryr.cz) Kolin, Czech Republic

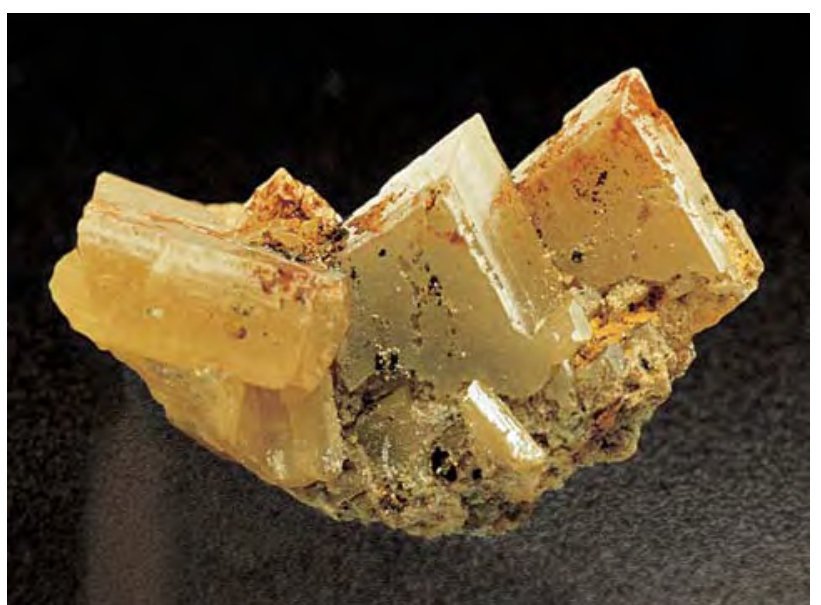

Figure 30. This well-formed $2.5 \mathrm{~cm}$ stolzite crystal was found at the Sainte Lucie Mine, France. Photo by J. Hyrsl.

Large scapolite from Tanzania. Gem-quality yellow scapolite has been known for years from the Mpwapwa area near Dodoma, Tanzania (see G. Graziani et al., "Observations on some scapolites of central Tanzania," Journal of Gemmology, Vol. 18, No. 5, 1983, pp. 379-381). Recently, a scapolite from this locality produced a stone that was notable for both its size and color. At $147.62 \mathrm{ct}$, the exceptionally clean cushion cut was a deep "golden" orange (figure 32). According to David Atkinson (of Terra, in Sedona, Arizona), who brought the stone to this contributor's attention, the rough was probably mined in the early 1990s, at the same time abundant smaller sizes also were available. He indicated that most scapolite crystals from Mpwapwa form elongated prisms (usually less than $2.5 \mathrm{~cm}$ in diameter). For maximum yield, stones usually are cut with their tables parallel to the c-axis, resulting in a "straw" yellow color. However, the scapolite shown in figure 32 was faceted from a 580 ct crystal cross section with a diameter of more than $6 \mathrm{~cm}$. As a result, the cutter

Figure 31. The Inder borate deposit in Kazakhstan is a source of many rare minerals, such as these sulfoborites. The faceted stone in the center is $1.27 \mathrm{ct}$. Photo by J. Hyrsl.

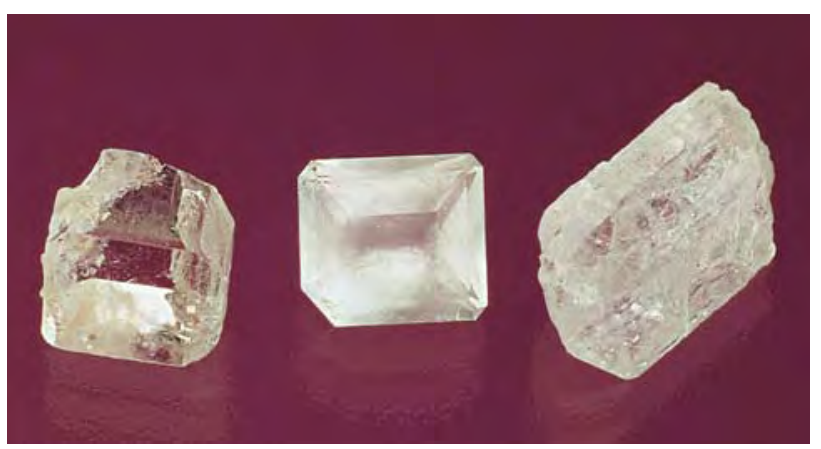




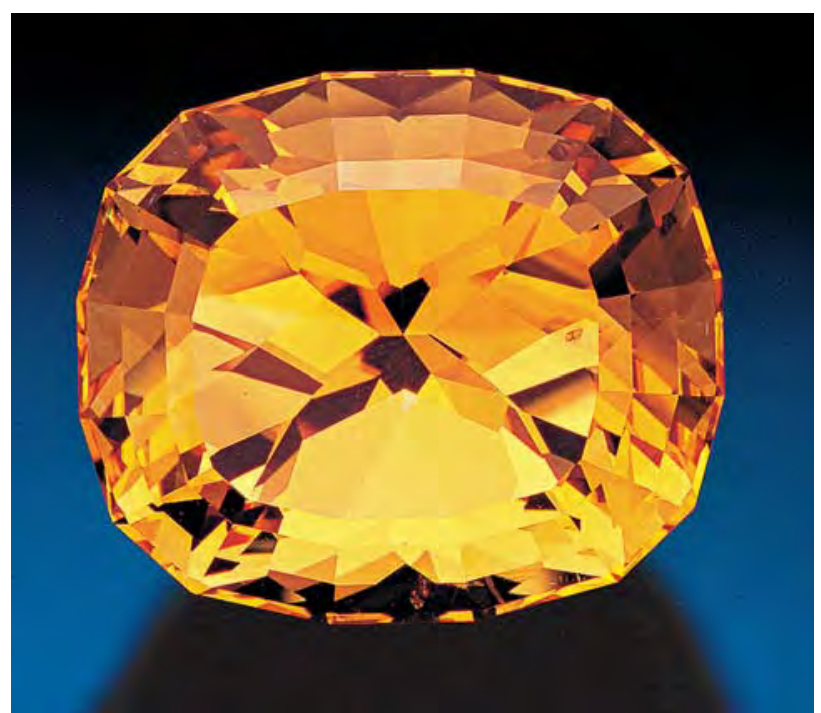

Figure 32. This $147.62 \mathrm{ct} \mathrm{scapolite} \mathrm{from} \mathrm{Tanzania,}$ faceted by Maria Atkinson, shows an unusually attractive deep "golden" orange color that results from cutting the stone with the table perpendicular to the c-axis. Photo by Ieff Scovil, (c) Terra, 2003.

could orient the stone to take advantage of the deeply colored c-axis direction.

$B M L$

Update on tanzanite mining by AFGEM. Since the discovery of tanzanite in the Merelani Hills of Tanzania in 1967, recovery of this attractive violet-blue gem (figure 33 ) has been subject to erratic production and resulting price fluctuations, due largely to informal mining using primitive methods. Several mining accidents over the past few years have claimed the lives of numerous workers (see, e.g., Summer 1998 Gem News, p. 145). Fortunately, the recent introduction of modern mining methods in one portion of the deposit has helped stabilize production. Since 1999, African Gem Resources Ltd. (AFGEM) of Johannesburg, South Africa, has been solely developing Block $\mathrm{C}$ of the tanzanite claims. Block $\mathrm{C}$ is the largest of the three main blocks covering an area of $8 \mathrm{~km}^{2}$; Blocks $\mathrm{B}$ and $\mathrm{D}$ are divided into $50 \leftrightarrow 50 \mathrm{~m}$ plots and mined informally. Block $\mathrm{A}$ is roughly $2 \mathrm{~km}^{2}$ and is mined by a Tanzanian individual.

As at the other claim blocks, extraction of tanzanite at Block $\mathrm{C}$ has historically been similar to artisanal mining of colored gem minerals at other primary deposits, with local miners braving dangerous conditions to extract the gem material as quickly and cheaply as possible. With these techniques, mine shafts are typically narrow, steep, and poorly ventilated - and the use of explosives releases noxious fumes that have proved deadly to the miners.

The new, mechanized operation at Block $\mathrm{C}$ is operated by AFGEM Tanzania, and is designed to maintain a high level of efficiency and safety. The miners work in large $(2$ $\leftrightarrow 3 \mathrm{~m}$ ) shafts with extensive roof bolting and timber support, as well as meshed concrete where necessary. All of the working faces are properly ventilated, and the miners are required to wear appropriate safety equipment. Although water is used during drilling to reduce dust, the use of underground channels, water collection pits, and large pumps minimizes the risk of flooding. Emergency equipment is provided in each shaft, and a well-equipped emergency clinic is available on site (although there have been no serious injuries to date). The miners are provided room and board in modern accommodations, with electricity supplied by a connection to the national grid, and back-up generators are available in the event of a power failure. The mine was in a developmental phase until the first quarter of 2003 and therefore has only recently begun regular production of tanzanite.

There are five active shafts on the property, known as JW, Main, Delta, CT, and Bravo. The most consistent production has come from the JW shaft, while the biggest finds have come from the Bravo shaft, where in July 2002 exquisite collector-quality crystals were extracted (some as large as 600 to 800 grams). In the six months leading up to September 30,2003, 12,311 tonnes of ore were extracted, which yielded 812,526 carats of gem-quality tanzanite. Thus, the ore grade during this period averaged 66 carats/tonne of mixed-quality gem material (classified into A, B, and C grades, based on transparency, color before heating, and size).

Underground blasting is strictly controlled. In tanzanite-rich zones, the larger visible crystals (known as "face pickings") are removed by hand, and the remaining material is processed via dense media separation (DMS). Ore is removed from the shaft by both fixed-rail and monorope

Figure 33. Tanzanite (here, $62.97 \mathrm{ct}$ ) has enjoyed strong demand in the gem trade, but has been subject to erratic production and resulting price fluctuations. Recent developments in the mining, recovery, and marketing of tanzanite from the Block $C$ portion of the deposit are helping to stabilize the production of this material. Courtesy of H. Krupp; photo by Maha Tannous.

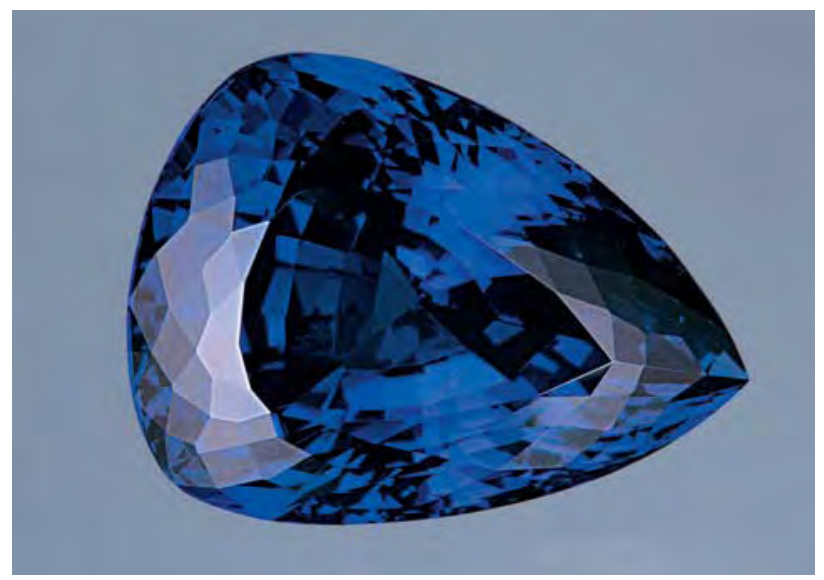




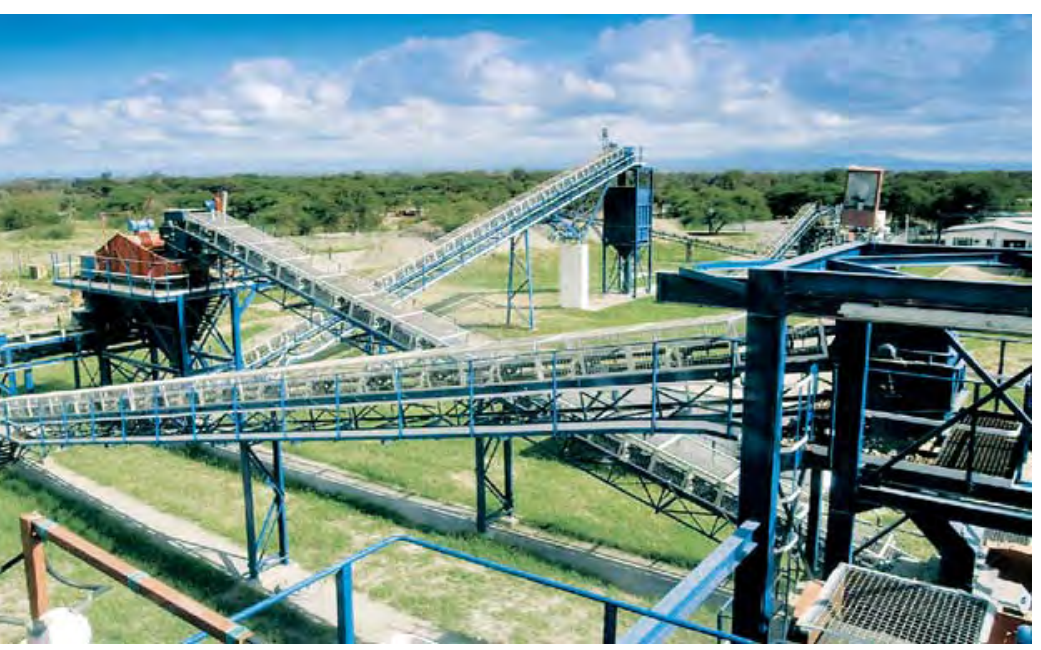

Figure 34. This customized processing plant has been converted by AFGEM from a former graphite plant to extract tanzanite. This photo, taken from the dense media separation area, shows a network of conveyor belts that eventually routes material to the sort house (far right), where it is hand-picked under stringent security measures. Photo by Reyno and Claire Scheepers.

systems. In the latter, the ore is placed into $10 \mathrm{~kg}$ sacks that are hooked to a cable which runs the full length of the tunnel. This automated cable moves the material slowly and continuously to the surface. The ore is then stored in large bins and discharged directly onto dump trucks for transport to the DMS plant (figure 34), which is situated 4 $\mathrm{km}$ from the mine at the source of the water supply (derived from an underground river). Once processed, the heavy fraction containing tanzanite is routed to a highsecurity sort house for hand picking. The tanzanite rough is either cut by in-house lapidaries or sold directly to large global customers (mostly cutters and dealers). The faceted tanzanite is heated on-site in a temperature-controlled kiln, whereas the rough is sold without being heat treated.

AFGEM Tanzania operates a continuous in-house training program whereby the locals are taught gem cutting by skilled professionals. One of the lapidary facilities (employing five cutters) is located in the processing plant, directly opposite the sort house, and a larger facility (with 15 full-time cutters) is situated at AFGEM's headquarters in Johannesburg.

Preventing stone theft remains a challenge. AFGEM Tanzania's mine employs stringent security systems and procedures in all producing areas and at shaft entrances, as well as at the plant, sort-house, and lapidary facility. An Xray body scanning system, which will be the first of its kind in Tanzania, has been specifically developed for the mine and will be operational by early 2004 .

The mine operates in compliance with an environmental impact study done in 1999. AFGEM is in the process of a multi-year environmental rehabilitation project, repairing much of the preexisting damage to the local landscape. Most of the ditches, open pits, and small tunnels dug by informal diggers have been filled in and are being replanted with indigenous flora.

AFGEM has created an ambitious grading and certification program for tanzanite. Each gemstone produced is evaluated using a proprietary grading system (according to cut, carat weight, color, and clarity) developed in conjunction with Independent Colored Stone Laboratories (Johannesburg), and is sold with a certificate of origin and authenticity issued by the Tanzanite Foundation. Although this system is currently used exclusively by AFGEM, steps are being taken to include tanzanite from all producers in this program.

Reyno and Claire Scheepers (rsc@sun.ac.za) Gemstone Research Centre University of Stellenbosch, South Africa

Figure 35. Fiberglass imitation cat's-eyes from China are available in many colors. Photo by A. Cossard.

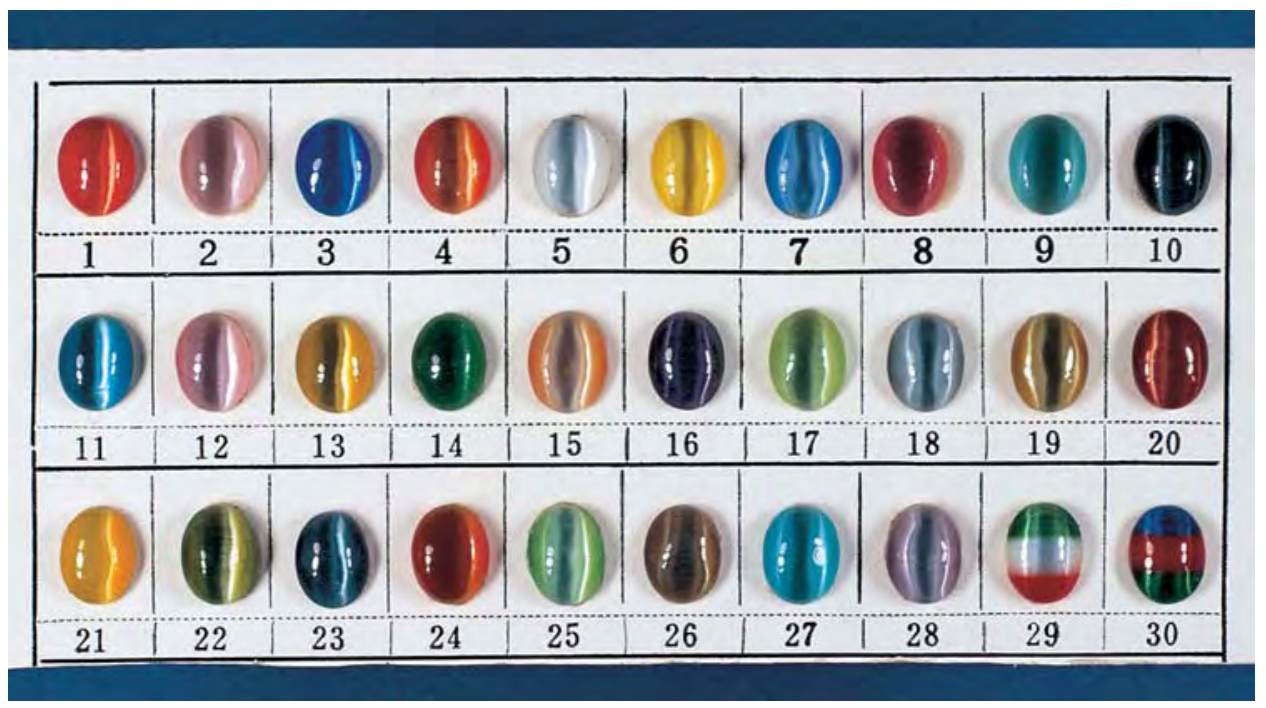




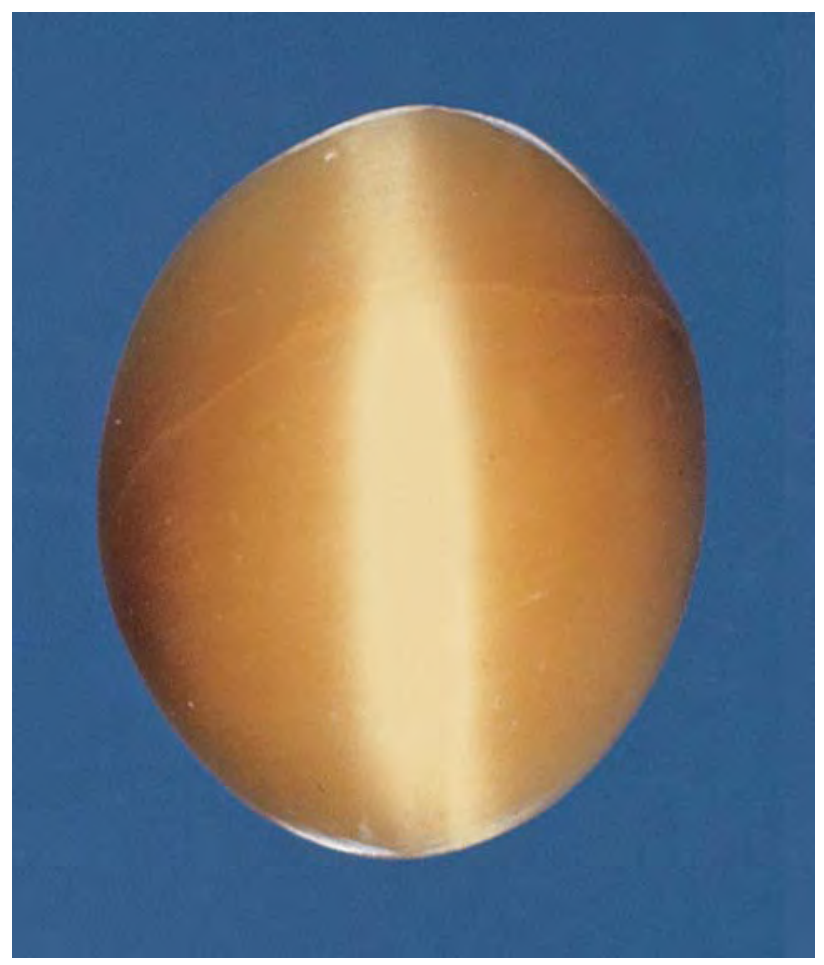

Figure 36. Some of the Chinese fiberglass cabochons provide a realistic imitation of cat's-eye chrysoberyl. Photo by $A$. Cossard.

\section{SYNTHETICS AND SIMULANTS}

Chatoyant glass cabochons from China. Since at least the early 1990s, fiberglass imitation cat's-eyes from China have been very common in the market. They are available in many colors (figure 35), some providing good imitations of cat's-eye chrysoberyl (various shades of yellow-brown in particular; see, e.g., figure 36). Even tricolor pieces have been developed (red-white-green and green-red-blue). They can be fashioned as cabochons or beads, but they may have other forms as well (e.g., for personal seals).

This contributor recently examined 30 of these Chinese imitation cat's-eyes, in both oval cabochons (ranging from approximately $8 \times 6 \times 2 \mathrm{~mm}$ to $18 \times 10 \times 4 \mathrm{~mm}$ ) and spherical beads (10 $\mathrm{mm}$ in diameter). The R.I. and S.G. (obtained by the hydrostatic method) values varied slightly according to color, as listed in table 1 . These values are well within those commonly observed for glass gem imitations, which in this contributor's experience range from about 1.46 to 1.70 in R.I., and from 2.3 to 4.2 in S.G.

Microscopic observation revealed that this material was indeed composed of parallel glass fibers. The fibers were not always straight, but rather were often slightly bent. In some samples, fractures and black spots of an undetermined nature made these imitations look more like natural gems.

The internal arrangement of fibers was easily visible with a Jeol 5800LV scanning electron microscope (SEM; see figure 37). Individual fibers were about $10 \mu \mathrm{m}$ across,

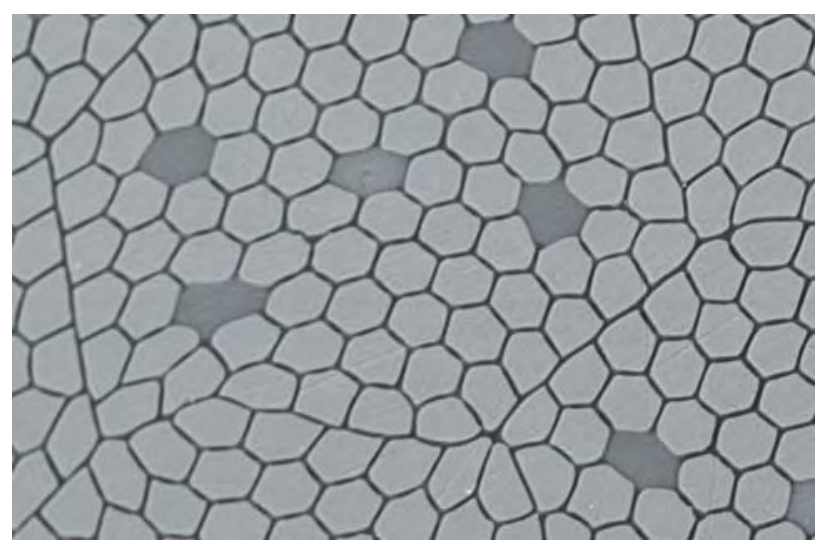

Figure 37. This scanning electron micrograph of a glass imitation cat's-eye from China clearly shows the bundled grouping of internal fibers. Colored fibers show up in this image as darker gray. The field of view is 200 $\mu \mathrm{m}$; each individual fiber is about $10 \mu \mathrm{m}$ across.

with an approximately hexagonal cross section. An unidentified material, which looked black in the electron micrographs, appeared to cement the fibers together. The fibers were bunched in larger, roughly hexagonal units, about $120-150 \mu \mathrm{m}$ wide, that were divided by rather straight black outlines. In each bunch, a small number of fibers (about 5 out of 90-100) were distinctly darker, and it is likely that these provided the color to the overall material. In some of the samples examined, the grouping of fibers was much less orderly, and they showed a more natural-looking cat's eye.

Qualitative microanalysis using the SEM's Princeton Gamma Tech energy-dispersive IMIX-PTS detector revealed the chemical composition of the glasses used, which are typical of "crystal"-type glass, that is, silicate glasses with $\mathrm{Pb}$ and $\mathrm{K}$. Also detected were small amounts of $\mathrm{Na}$ and $\mathrm{Ba}$, and traces of $\mathrm{Al}$. The fibers themselves had a similar composition. However, the colored fibers were systematically poorer in $\mathrm{Pb}$ and richer in $\mathrm{K}$ than the noncolored ones, and it is possible that they contained a coloring agent as well (see below). The cementing material

TABLE 1. R.I. and S.G. values of Chinese fiberglass imitation cat's-eyes.

\begin{tabular}{lll}
\hline Color & R.I. & S.G. \\
\hline Orangy red & 1.52 & 2.65 \\
Blue-green & 1.53 & 2.84 \\
"Cobalt” blue & 1.56 & 2.99 \\
Light blue & 1.56 & 3.11 \\
Violetish brown & 1.57 & 3.12 \\
Gray & 1.57 & 3.14 \\
White & 1.57 & 3.18 \\
Dark green & 1.58 & 3.20 \\
Pink & 1.58 & 3.20 \\
\hline
\end{tabular}


was very poor in $\mathrm{Pb}$ and richer in $\mathrm{Na}, \mathrm{Al}$, and $\mathrm{K}$ than regular fibers; all fibers had a more elevated but still modest amount of $\mathrm{Ba}$.

In some cases, microanalysis revealed transition metal(s) in the color-bearing fibers. Black was associated with traces of $\mathrm{Mn}$; green with $\mathrm{Cu}, \mathrm{Cr}$, and/or $\mathrm{Fe}$; yellow to orange to brown with $\mathrm{Fe}$; and bright blue with Co. For other colors, such as pink and red, there was no additional transition element, but rather more lead and zinc, which are not classically associated with such colors.

Raman spectroscopy, obtained on a Bruker RFS100 Fourier transform spectrometer, demonstrated the amorphous nature of the material. The spectrum consisted of essentially two broad bands at about 800 and $290 \mathrm{~cm}^{-1}$. The width of the bands (at almost $200 \mathrm{~cm}^{-1}$ ) is typical of amorphous materials such as glasses. This glass is apparently anhydrous, as no broad band was observed on the spectrum at about $3500 \mathrm{~cm}^{-1}$.

The identification of these chatoyant glass cabochons is straightforward, by observing their appearance with the unaided eye (i.e., unnatural chatoyancy and unusual color in some cases) and the gemological microscope (the presence of parallel glass fibers).

New synthetic opal varieties. Kyocera Corp. of Kyoto, Japan, has been manufacturing synthetic opals since the early 1980s. They recently provided the GIA Gem Laboratory with examples of their new line of synthetic opals, which, in addition to black and white, includes

Figure 38. These eight cabochons (2.41-2.68 ct) are examples of the new synthetic opals being produced by Kyocera. The company has been producing the black and white synthetic material since the 1980s, but it recently introduced semitransparent varieties, including "fire" and "jelly" synthetic opals. Courtesy of Kyocera Corp.; photo by Maha Tannous.

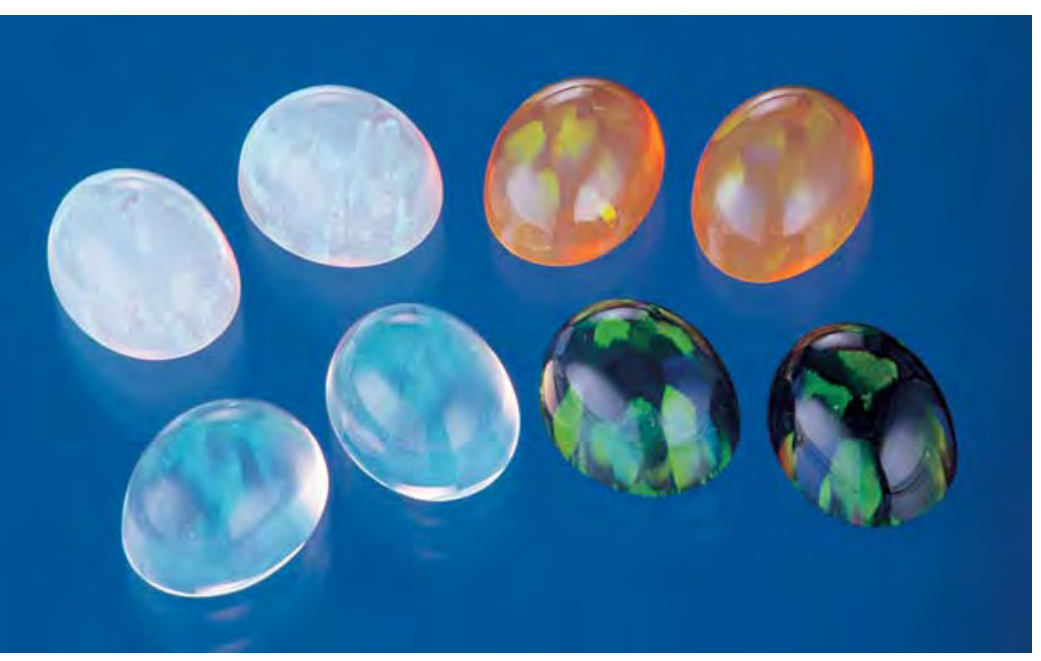

"fire" and "jelly" varieties that are significantly more transparent than most other non-impregnated synthetic opals.

Eight oval double cabochons (two of each type; figure 38) were provided, ranging from 2.41 to $2.68 \mathrm{ct}$. Gemological properties were collected on one sample of each variety, as follows: color-white, near-colorless, orange, and black, with all samples displaying play-ofcolor; diaphaneity-semitransparent (orange and nearcolorless cabochons), semitransparent to translucent (white), or translucent to semitranslucent (black); optic character-singly refractive with weak to moderate anomalous double refraction; refractive index-spot readings of 1.46 to 1.47 ; hydrostatic specific gravity2.22-2.27; and no reaction to the Chelsea filter. The white and near-colorless cabochons fluoresced very weak to weak chalky blue (slightly stronger to short-wave UV), the orange cabochon luminesced very weak red (also slightly stronger to short-wave UV), and the black cabochon was inert to both long- and short-wave UV; none of the samples exhibited phosphorescence. When viewed with a desk-model spectroscope, all samples had a band at 550 $\mathrm{nm}$ and a line at $580 \mathrm{~nm}$. Three of the four exhibited a band at $500 \mathrm{~nm}$, whereas the orange cabochon showed only general absorption to $500 \mathrm{~nm}$. In addition, lines at 600 and $620 \mathrm{~nm}$ were noted for the near-colorless and black cabochons, respectively. With the microscope, all samples showed the "chicken-wire" or "snake-skin" pattern and columnar structure that are typical of most synthetic opals.

According to Kyocera, these samples were not polymer impregnated, and this was supported by FTIR spectroscopy. None of the polymer-related absorption features documented in some other synthetic opals produced by Kyocera (as described in the Summer 1995 Gem News, pp. 137-138) were found in any of the four samples. The absence of polymers was further supported by the higher S.G. values measured for these samples (2.22-2.27), as compared to those recorded for the earlier polymerimpregnated material (1.88-1.91).

Overall, the gemological properties of these synthetic opals were very close to those expected for natural opal. However, the identification of the material is not difficult due to the presence of distinctive growth features typical of many laboratory-grown opals.

\section{Elizabeth P. Quinn}

Plastic imitations of a walrus tusk and a sperm whale tooth. Recently, the SSEF Swiss Gemmological Institute received for testing two specimens that appeared to be some sort of teeth. The larger one (about $40 \mathrm{~cm}$ and 665 grams) strongly resembled a walrus tusk, while the smaller one (about $16 \mathrm{~cm}$ and 390 grams) looked like a sperm whale tooth (figure 39), complete with aging striations and accumulated dirt. Both items were carved with motifs of historical sailing vessels and whaling, with the inscriptions "Ship Sachen 1856-59" on the larger item and "The 
bark Veronica" and "all in a days work" on the smaller item. They were reportedly part of a collection of several similar looking items, including elephant ivory.

By comparing the specimens with an authentic sperm whale tooth (figure 40), doubts about their identity immediately arose. The "pulp cavities" at the ends of both specimens showed no roots where they would have attached to the jawbone of a walrus or a sperm whale. Patterns such as cross-hatches, concentric lines, and dots, all of which are typical for ivory or teeth (see $M$. Campbell-Pedersen, Gem and Ornamental Materials of Organic Origin, Butterworth-Heinemann, Oxford, UK, 2003), also were not present. Even more suspicious, a broken fragment of the "walrus tusk" showed a perfect conchoidal fracture, which was interrupted by a layer of crushed material and several air bubbles (figure 41). Conchoidal fractures are typical for some homogeneous and amorphous substances like plastic, but not for organic substances, which show structured fracture planes with internal patterns.

Gemological testing quickly confirmed that both objects were plastic. Contact with a hot point produced a distinct acrid plastic smell. Testing with a hydrostatic balance revealed a specific gravity of 1.26 , which is distinctly lower than the S.G. of walrus tusks and sperm whale teeth (typically 1.85).

The plastic imitations were further analyzed chemically (EDXRF), structurally (FTIR and Raman spectroscopy), and microscopically (SEM), and the results were compared with those of sperm whale teeth, ivory, and plastics. The main constituents of plastic (carbon, oxygen, and hydrogen) cannot be analyzed by EDXRF; however, these analyses did reveal information about the coloring agent of the plastic in both samples. With titanium dominant over other transition metals ( $\mathrm{Mn}, \mathrm{Fe}, \mathrm{Co}$ ) as well as $\mathrm{Si}, \mathrm{K}, \mathrm{Ca}, \mathrm{S}, \mathrm{Cl}$, the

Figure 40. Comparison with an authentic sperm whale tooth (left) raised doubts about the identity of the carved plastic imitation (right). Photo by $H$. A. Hänni, (c) SSEF.

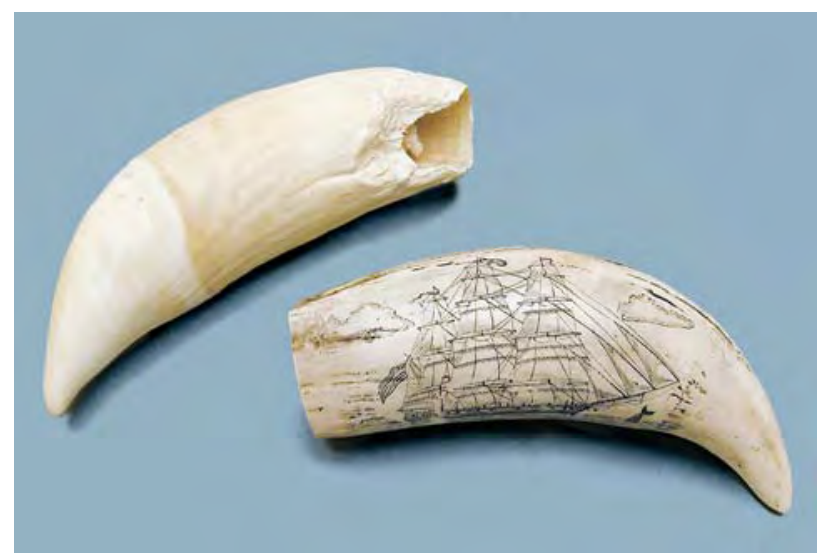

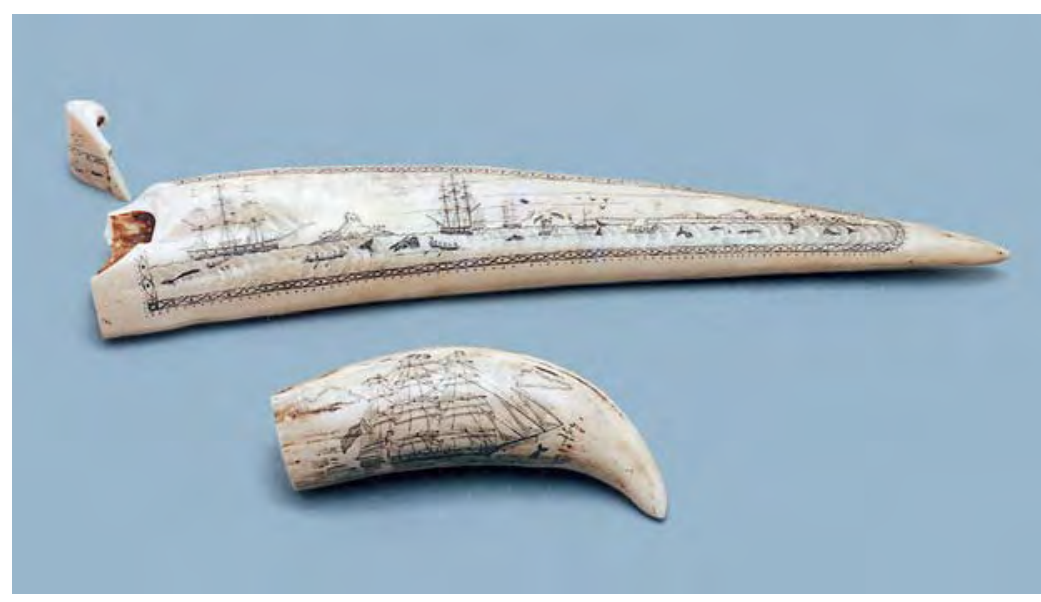

Figure 39. These specimens, resembling a walrus tusk (top, $40 \mathrm{~cm}$ long) and a sperm whale tooth (bottom, $\sim 16 \mathrm{~cm}$ long) proved to be plastic imitations. Photo by M. S. Krzemnicki, (C) SSEF.

agent is probably titanium-white, a well-known dye.

In the authentic sperm whale tooth, $\mathrm{Ca}, \mathrm{P}$, and some Fe were found, which are the main constituents of teeth. Ca also was detected in the "walrus tusk" imitation, apparently due to the layer of crushed material mentioned above, which proved to be calcite (see below). This contributor suspects that the crushed calcite was added to the plastic to produce a density and a chemical signal somehow similar to those of natural teeth.

FTIR analyses (by Marco Nägelin, von Roll Isola, Switzerland) on the laboratory-created items were distinctly different from those of the sperm whale tooth, showing a typical polyester (unsaturated isophthalate) fingerprint with peaks at $3061,3027,2925$, and $2853 \mathrm{~cm}^{-1}$. Raman

Figure 41. A broken fragment of the plastic "walrus tusk" showed conchoidal fractures, air bubbles, and a layer of crushed calcite crystals, proving its manufactured nature. Photo by H. A. Hänni, (c) SSEF.

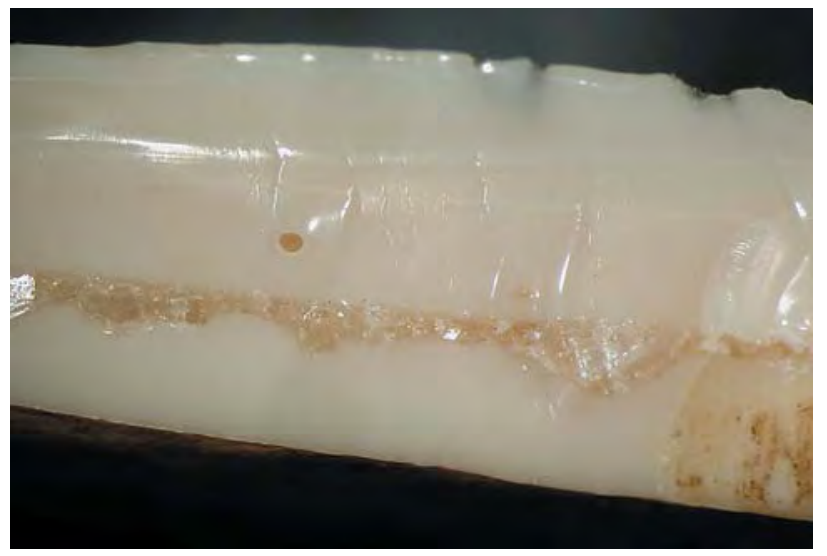



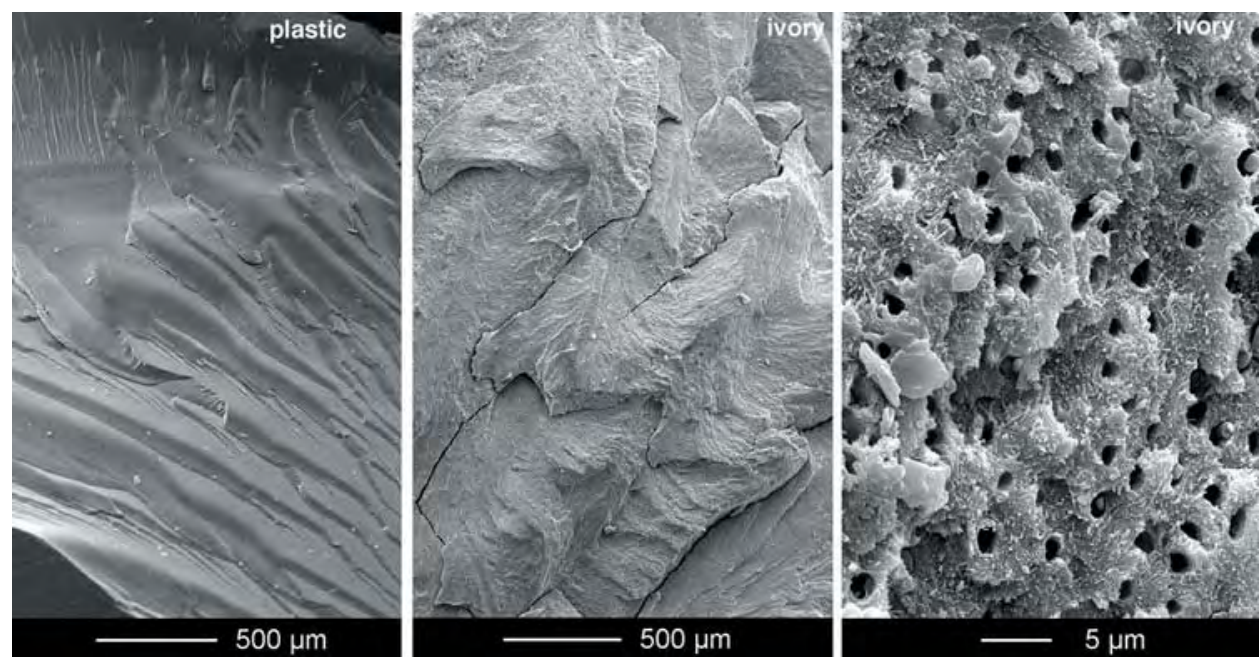

Figure 42. SEM micrographs demonstrate the obvious differences between the conchoidal fracture of the plastic "walrus tusk" (left) and the irregular splintery fracture (middle) and porous microstructure (right) in ivory (elephant tusk). Magnified $50 \times$ (left and center), 250× (right); (C) SEM lab oratory, University of Basel, Switzerland.

spectroscopy (using an argon laser at $514 \mathrm{~nm}$ ) was carried out on the layer of crushed material within the plastic items. These revealed peaks at 1097, 300, and $174 \mathrm{~cm}^{-1}$, typical for carbonates (calcite to magnesite series). Together with the presence of Ca detected by EDXRF, this crushed material was identified as calcite. FTIR measurements on the plastic confirmed the presence of water molecules (peaks at 5284, 5250, 3471, and $3225 \mathrm{~cm}^{-1}$ ).

SEM micrographs were taken to compare the surface structures of the plastic items with those of teeth. Figure 42 shows the fracture surfaces of the plastic "walrus tusk" (left) and ivory (center). The plastic imitations showed conchoidal fracture planes with step-like patterns, but no internal structures. In contrast, ivory (and sperm whale tooth) has a rather irregular splintery fracture. As seen under higher magnification (figure 42, right), the microstructure of ivory consists of a regular pattern of hollow channels. Similar structures are found in other types of teeth.

By careful observation and testing using standard gemological methods, the experienced gemologist will easily identify these plastic imitations, although their visual appearance can be quite convincing.

Michael S. Krzemnicki (gemlab@ssef.ch) SSEF Swiss Gemmological Institute Basel, Switzerland

\section{CONFERENCE REPORTS}

Antwerp Diamond Conference. The second annual Antwerp Diamond Conference was held November 3-4, 2003. The primary theme was marketing and branding of diamonds; however, many speakers also addressed the broader problems of industry finance and distribution. They agreed that the diamond industry is in the process of unprecedented change, which will forever alter the ways it does business and inevitably cause a spate of mergers and consolidations.

Maurice Tempelsman, chairman of Lazare Kaplan International, New York, told the audience of some 500 that the changes instigated since the De Beers Diamond
Trading Company (DTC) abandoned its traditional custodianship of the market have increased risk throughout the diamond pipeline. Yet, the ability of the industry to deal with such risks has "not yet been tested." The DTC, he said, essentially sold off its well-capitalized, non-debtfinanced diamond stockpile to its clients, many of whom financed their purchases by increasing debt as they piled up inventory. These firms have compounded their problems by making "imprudent" deals with retailers that include very long payment terms and memo purchases. Retail margins for diamond jewelry have been shrinking, he added, leading to decreased profitability.

Peter Gross, vice president of the International Diamond \& Jewelry Group of ABN AMRO Bank, Antwerp, said that the industry is in an unhealthy situation, with rough diamond prices rising due to manufacturers' desire to keep their operations going, while at the same time polished diamond inventories-and the debts that finance them-have also been increasing. He explained that the industry suffers from an excess manufacturing capacity that will eventually cause some cutting operations to shut down or merge with other companies. "The quality of industry bank debt has declined in the past year," he said. "Companies must now focus more on driving sales instead of getting supplies."

Gareth Penny, DTC sales and marketing manager in London, emphasized that effective marketing and branding of diamond jewelry is the best way to break out of the discount trap that is sapping margins. In presenting the principles of branding, he showed examples of diamond jewelry advertisements featuring cluttered arrays of pieces with discount prices splashed throughout. He contrasted that with a Gucci advertisement showing a stylish woman enjoying a new handbag. "Who in the world discounts Gucci?" he asked, adding that even some U.S. mass merchandisers are starting to get the message that diamond jewelry should be advertised like a luxury product.

Paul Goris, vice president of Antwerp Diamond Bank, stressed that marketing programs require "big money," so only the largest, best-capitalized firms will be able to fund 
their own branding initiatives. He expressed concern that other companies, even fairly large DTC sightholders, will draw funds from their business operations that would normally go to maintaining inventories and use them for marketing activities that may not have a swift return. He also stressed that marketing and branding initiatives must be based on solidly researched customer need and be professionally executed.

Pierre Gurdjian, a specialist for the business consulting firm McKinsey \& Co., Antwerp, told the audience that major consolidations are inevitable in the diamond industry, because many firms will not be able to sustain the high costs of marketing and branding activities without taking on partners or merging with larger players. He noted that of the more than 100 new diamond cuts introduced in the past few years, only about five are truly distinctive with any consumer recognition. Branded diamond jewelry lines have even less consumer recognition, and thus for the most part their advertising campaigns "are not a sustainable platform for sales growth." At the same time, he noted that mass retailers are "trampling" their diamond suppliers, forcing diamond manufacturers to give very favorable terms while luxury companies are faced with declining margins. The skills to carry out effective branding strategies are currently lacking in the diamond industry, Mr. Gurdjian said, so diamond manufacturers must look to other fashion and retail industries to make them work

Danny Horowitz, president of $\mathrm{IDH}$, an Antwerp-based rough diamond dealer, questioned whether diamonds could ever be properly branded since they are inherently a generic product. He noted that even in Japan, where consumers are the most brand-conscious, there is "branding fatigue." The branding initiatives, he added, have thus far failed to alleviate the current inventory overhang in the market. Instead, they have brought increases in industry debt that are causing liquidity problems throughout the pipeline.

Maxim Shkadov, first deputy director general of Krystall Smolensk, a diamond cutting operation in Smolensk, Russia, told the audience that his firm plans to promote Russia's tradition of well-cut diamonds as a brand, adding that its 2003 sales of polished were running $3.3 \%$ ahead of 2002 's total of $\$ 250$ million. He added that the domestic Russian diamond market grew $49 \%$ in the past two years, thanks in part to the country's newly wealthy, who respond strongly to the company's advertising slogan, "Measure your success in carats."

Other producers, represented by Nigel Jones (general manager of marketing, Rio Tinto's Diamond Product Group), Graham Nicholls (manager of branding operations, BHP Billiton Diamonds Inc.), and Stephen Lussier (executive director of marketing, DTC), presented their own diamond branding strategies. Mr. Jones, whose company owns majority shares in Australia's Argyle mine and Canada's Diavik mine, says its brand will provide assurances to consumers that its operations adhere to First World standards and include high business ethics. Mr. Nicholls noted that BHP's CanadaMark emphasizes the Canadian origin of diamonds from its Ekati mine. Mr. Lussier stressed that the diamond branding revolution "is irreversible" and essential to increasing diamond jewelry sales.

Hidetaka Kato, chairman of Kashikey Co. Ltd., Tokyo, described his company's current campaign to brand a line of brown diamond jewelry. Aimed at the casual-wear market for women's self-purchase, the program carries the tag line "free and easy" and promotes a product line that did not exist before in Japan.

Nadja Swarovski, vice president of international communications with D. Swarovski \& Co., Wattens, Austria, outlined her company's strategy for introducing a brand of luxury crystal aimed at the fashion accessories market, and Isabelle Guichet of Van Cleef \& Arpels, Paris, told how this well-established high-market jewelry house was pursuing younger buyers while keeping its signature identity.

Bernie Sensale, senior vice president of marketing with Zale Corp., Irving, Texas, said that all marketing decisions must be based on understanding consumers' decisions. He predicted that the bridal market will grow an estimated $14 \%$ over the next three years and stressed that $78 \%$ of all first-time brides in the U.S. receive a diamond engagement ring.

Former U.S. president Bill Clinton, in his keynote address, praised the diamond industry for its initiatives in ending the trade in conflict stones through the Kimberley Process. "The industry has put aside traditional differences for its common interests, and is working to end problems such as AIDS in Africa and conflict diamonds." He added that it is well worth the money spent to combat these problems, because they ultimately bring a more stable, peaceful world based on shared values, benefits and interests.

\section{Russell Shor (russell.shor@gia.edu)} GIA Senior Industry Analyst

Rapaport International Diamond Conference. On October 20, 2003, the first Rapaport International Diamond Conference was held in New York City, with a standingroom-only crowd of more than 250. The conference was dominated by two controversial issues: a growing shortage of rough diamonds and the entry of synthetic diamonds into the consumer market.

Moshe Leviev, managing director of LLD, Ramat Gan, Israel, indicated that shortages of rough diamonds over 20 points, especially high-quality goods, will be a dominant factor for the next decade. He added that there will be no major new diamond mines coming on line for five to eight years at minimum, so shortages will get worse as demand rises. Mr. Leviev stressed that the De Beers DTC's Supplier of Choice initiative, which requires sightholders to fund costly marketing and advertising campaigns to increase diamond jewelry sales, will take their toll on diamond manufacturers. "The market cannot support 130 
different diamond brands, so we are likely to see many companies bankrupted by high costs."

Dilip Mehta, chairman of Rosy Blue, Antwerp, noted that the industry is entering an era of fundamental change, from an excess of supply over demand, to the reverse. "We've seen how rising demand helped De Beers liquidate nearly all its buffer stocks of diamonds, and assuming that demand keeps rising, production will not be able to keep up." Mr. Mehta warned that prices for diamonds will rise significantly in coming years, beyond the point where retailers and suppliers will be able to absorb them. S. Lynn Diamond, executive director of the Diamond Promotion Service, New York, said that the DTC has set a growth target of $50 \%$ in worldwide diamond jewelry sales- $\$ 84$ billion-by the decade's end. Ken Gassman, director of research, Rapaport Group, New York, added that it is apparent that most of this growth will come from price increases, not rising unit sales, because of supply shortages.

Elliott Tannenbaum, manager of Schachter-Namdar, Israel, said that the shortages in quality rough diamonds will ultimately lead to a major reorganization of the industry, with major retailers and diamond suppliers vertically integrating. "By 2010, we will see suppliers taking major stakes in retail jewelers. By 2028, we will see a situation like the oil companies, where a few major players have operations integrated from mining to retail. Retailers not attached to major suppliers may have difficulty finding supplies." Martin Rapaport, publisher of Rapaport Diamond Report, New York, stressed that future retail competition will be geared more to marketing and branding initiatives, than to price. "In short, strategy will be more important than skill."

However, Peter Gross, vice president of the International Diamond \& Jewelry Group of ABN AMRO Bank, Antwerp, said that the future is less worrisome than the current industry debt and inventory situation. He maintained that an excess manufacturing supply is causing the current climb in rough prices, even as large quantities of polished are still sitting in dealers' safes. "The rising cost of rough and lengthening credit terms of U.S. retailers have contributed to a very sharp rise in industry debt during the past year." Further, he indicated that increases in the cost of rough and in the inventory of polished stock are squeezing profitability from the industry. He asserted that diamond manufacturers must rein in the ever-lengthening credit terms demanded by retailers.

Synthetic diamonds from Gemesis Corp. of Sarasota, Florida (figure 43), and Apollo Diamond Inc., Boston, Massachusetts, were the other main subject of discussion. Ed Bridge, president of Ben Bridge Jeweler, Seattle, said that increasing numbers of synthetics and treated gems in the market are a challenge to retailers, adding that disclosure of such goods is necessary to maintain consumer confidence. Carter Clarke (chairman, Gemesis) and

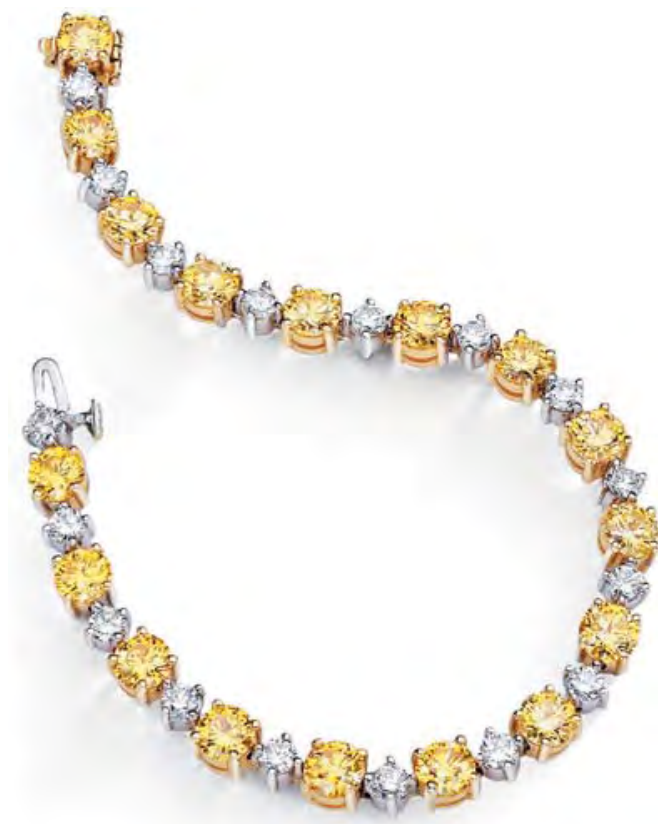

Figure 43. Synthetic diamonds are being set into finequality jewelry, as shown by this tennis bracelet set with colorless natural and yellow Gemesis created diamonds, set in $18 \mathrm{~K}$ gold. The bracelet contains 10.62 carats of created diamonds and 3.99 carats of natural diamonds. Courtesy of Gemesis Corp.

Bryant Linares (president, Apollo) both promised "full disclosure down the line" for all their products, including laser inscriptions identifying them as lab-created diamonds. Both also stressed that their products are designed to fill a consumer desire for high-quality diamonds at affordable prices. Mr. Clarke said his products will be priced similarly to G-color, VS-clarity diamonds of comparable weight; Mr. Linares said that Apollo had not yet determined prices for their products. However, Terry Burman, CEO of Signet Group, London, believed that the prices consumers will pay for synthetic goods cuts off far below manufacturer expectations. "We've found little consumer interest above \$500."

William E. Boyajian, president of GIA, stressed that there is a legitimate place in the industry for synthetic and treated gems, provided they are disclosed. However, he added, there are rogue treaters who refuse to disclose treatments. The consequences of non-disclosure can be major, he noted, citing the damage to the emerald market caused by new filling practices, the collapse in prices for beryllium-diffused corundum, and the "volatile" reaction of the trade to HPHT-treated diamonds.

Russell Shor 


\section{ANNOUNCEMENTS}

2004 AGTA Cutting Edge Award winners. The winners of the 2004 American Gem Trade Association Spectrum and Cutting Edge Awards were announced November 17 in New York City. The competition was held October 31-November 2, 2003, and a total of 564 submissions in all categories were considered.

The winners of the Cutting Edge Awards were, by division: Classic Gemstone: Allen Kleiman, A. Kleiman \& Co., Boulder, CO; All Other Faceted Gemstones: Ben Kho, Kho International Ltd., Decatur, GA; Phenomenal Gemstones: Jeffrey Bilgore, Jeffrey Bilgore LLC, New York; Faceting: John Dyer, Precious Gemstones Co., Eau Claire, WI; Carving: Dalan Hargrave, Gemstarz, Spring Branch, TX; Combination: Andrew Gulij, Gemfix, Big Bear City, CA; Pairs and Suites: Matt Casteen, Raleigh, NC; Objects of Art: Ralph Wobito, Wobito Gems Ltd., Stouffville, Ontario, Canada.

Winning entries will be displayed during the 2004 AGTA GemFair Tucson, February 4-9, 2004.

Professional Jeweler's Stone of the Year. Starting in 2004, Professional Jeweler will select a Stone of the Year to be featured in the magazine's January issue. The stone will be chosen according to its contemporary importance in the gem trade and will be covered in a feature article with abundant photos showing its diversity of appearance, a pricing guide, and a fashion section. The initiative is designed to create excitement about colored stones. The 2004 Stone of the Year is sapphire (figure 44).

Afghanistan/Pakistan gem tour. In August-September 2004, Gary Bowersox of GeoVision Inc., Honolulu, Hawaii, will lead a three-week tour to colored gem deposits and marketplaces in Pakistan and Afghanistan. Visit www.gemsafghan.com/guidedtours.htm.

\section{Conferences}

PDAC 2004. The Prospectors and Developers Association of Canada convention will take place March 7-10 in Toronto. Diamonds will be featured in a session called "Diamonds: Rooting Around for Carats," and also in presentations on geophysics and legal issues. The guest program will include a jewelry-making workshop. Visit www.pdac.ca/pdac/conv.

ICNDST-9 in Tokyo. The 9th International Conference of New Diamond Science and Technology will be held at Waseda University in Tokyo, Japan, March 26-29, 2004. Among the topics covered will be growth of diamond and diamond-like materials, as well as diamond processing and characterization. Visit www2.convention.co.jp/ICNDST-9.

BASELWORLD 2004. The BASELWORLD show will be held April 15-22 in Basel, Switzerland. GIA will host

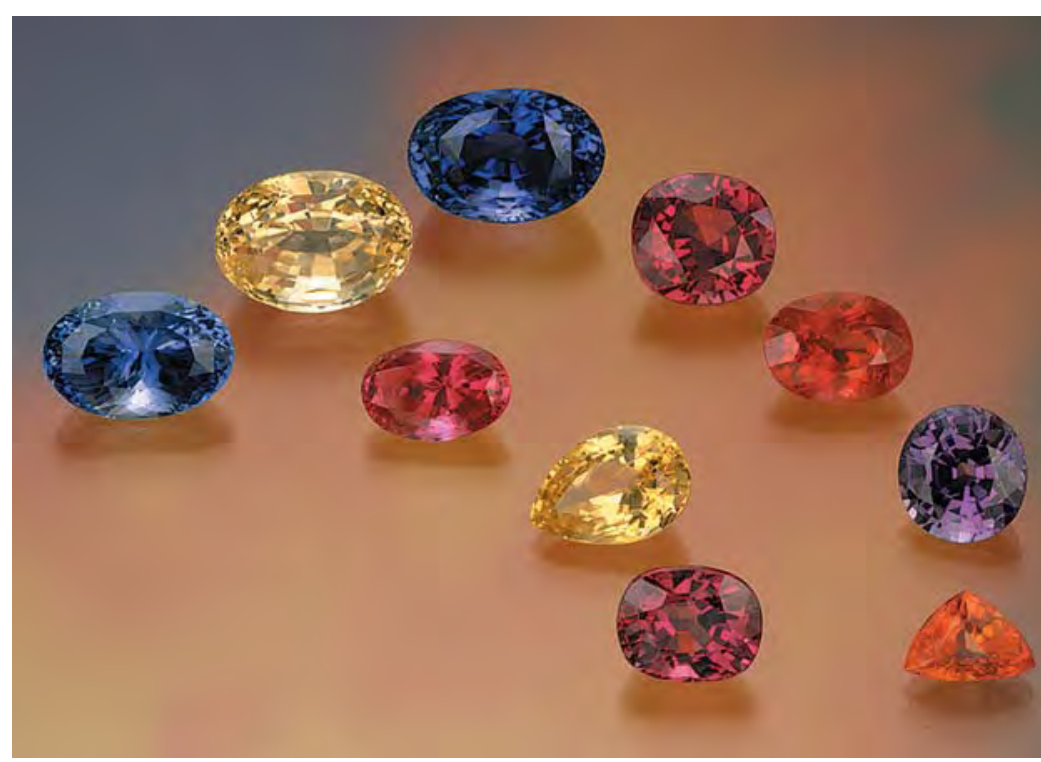

Figure 44. Professional Jeweler's Stone of the Year for 2004 is sapphire. This assortment, ranging from approximately 3 to $8.59 \mathrm{ct}$, illustrates the diversity of color shown by natural-color sapphires from various sources. Courtesy of James Alger Co. Inc.; photo by Robert Weldon/Professional Jeweler.

GemFest Basel on April 17, 4-6 pm at the Basel Convention Center, Hall Montreal. The program will include an update from the GIA Gem Laboratory, as well as an "Update on GIA's Diamond Cut Research." The event will conclude with a panel discussion, and be followed by a reception. During the show, Gems 4 Gemology editor-in-chief Alice Keller will be available at the GIA Booth in Hall 2, Stand W23. Visit www.baselshow.com.

GAC-MAC joint annual meeting. On May 12-14, 2004, in St. Catherines, Ontario, Canada, the Geological Association of Canada and the Mineralogical Association of Canada will co-host a conference that will include special sessions titled "Kimberlites and Diamonds: New Discoveries and New Developments" and "Rare Element Geochemistry and Ore Deposits." The latter session will include a short course and field trip to visit granitic pegmatites in Ontario, Canada. Visit www.stcatharines2004.ca.

GAA conference. The 58th Annual Federal Conference and Seminar of the Gemmological Association of Australia will take place May 13-16, 2004, in Perth, Australia. Visit www.gem.org.au.

Santa Fe Symposium. On May 23-26, 2004, in Albuquerque, New Mexico, this symposium will offer technical information on jewelry manufacturing procedures. Visit www.santafesymposium.org. 
20th Colloquium of African Geology. Gemstones and small-scale mining will be among the topics covered in a seminar on "Earth Resources and Sustainable Development of Africa" at this conference in Orléans, France, June 2-7, 2004. Visit http://cag20.brgm.fr.

GEORAMAN 2004. This conference will take place June 6-11, at the University of Hawaii Manoa Campus in Honolulu. Applications of Raman spectroscopy to the identification of gem materials and minerals in ancient arts and archaeology will be among the wide range of topics covered. Visit www.soest.hawaii.edu/GEORAMAN2004.

Geoscience Africa 2004. Hosted by the University of the Witwatersrand in Johannesburg, South Africa, July 12-16, this conference will feature a symposium titled "Kimberlites, Diamonds and Mantle Petrology." Field trips to the Cullinan diamond mine and alluvial diamond deposits along the Orange River will be offered. Visit www.wits.ac.za/geoscienceafrica.

International Geological Congress. The 32nd Session of the International Geological Congress will be held August 20-28, 2004, in Florence, Italy. Symposia are planned that will cover gem materials, inclusions in minerals, and mineral spectroscopy. Visit www.32igc.org/default1.htm.

Gems of Pacific continental margins. The International Association on the Genesis of Ore Deposits will host a symposium titled "Gem Deposits Associated with the Pacific Continental Margins" at the Interim IAGOD Conference on Metallogeny of the Pacific Northwest: Tectonics, Magmatism \& Metallogeny of Active Continental Margins. The conference will take place September 11-19, 2004, in Vladivostok, Russia. Visit www.fegi.ru/IAGOD.

Diamond 2004. A review of the latest scientific and technological aspects of natural and synthetic diamond (as well as related materials) will take place at the 15th European
Conference on Diamond, Diamond-Like Materials, Carbon Nanotubes, Nitrides \& Silicon Carbide, September 12-17, in Riva del Garda, Italy. Visit www.diamond-conference.com.

ICAM 2004 in Brazil. The 2004 International Congress on Applied Mineralogy will be held in Águas de Lindóa, Brazil, September 19-22, and will include a special session on gem materials. Pre- and post-conference field trips will tour colored gemstone and diamond deposits in the Ouro Preto and Diamantina areas, as well as agate and amethyst mines in Rio Grande do Sul State. Visit www.icam2004.org.

\section{Exhibits}

Turquoise at the San Diego Museum of Man. "The Turquoise Path/El Camino Turquesa: The Story of Turquoise in the Native American Southwest" will be on display at the Museum of Man in San Diego, California, through April 2004. The exhibit examines turquoise jewelry-making techniques and showcases the unique historical, social, cultural, and economic significance of this gem material. Visit www.museumofman.org.

Jade at The Field Museum. The newly renovated "Hall of Jade" will return to permanent exhibition at The Field Museum in Chicago beginning March 12, 2004. Featuring a collection of nearly 500 jade artifacts, the display explores the gem as a cultural symbol of prosperity, power, and virtue in China for more than 8,000 years. Visit www.fieldmuseum.org.

\section{ERRATUM}

The list of $2003 G \Theta G$ Challenge Winners in the Fall 2003 issue (p. 251) contained two errors. Veronika Riedel's name was misspelled, and Arthur Spellissy, of South Freeport, Maine, was mistakenly placed in the list of winners for Maryland. Gems ef Gemology apologizes for the errors.

\section{MANUSCRIPT REVIEWERS}

GEMS \& GEMOLOGY requires that all articles undergo a peer review process in which each manuscript is evaluated by at least three experts in the field. This process is vital to the accuracy and readability of the published article, but it is also time consuming for the reviewer. Because members of our Editorial Review Board cannot have expertise in every area, we sometimes call on others in our community to share their intellect and insight. In addition to the members of our Editorial Review Board, we extend a heartfelt thanks to the following individuals who reviewed manuscripts for $G \& G$ in 2003:

Dr. Curt W. Beck

Mr. George Bosshart

Ms. Dona Dirlam

Mr. Richard Fassler
Ms. Cecilia Gardner

Mr. Al Gilbertson

Dr. Gaston Giuliani

Mr. John Kim
Dr. Frank C. Hawthorne

Ms. Karin Hurwit

Mr. Bert Krashes

Ms. Terri Ottaway
Mr. Russell Shor

Dr. Chris Welbourn

Mr. Benjamin Zucker 